\title{
High Prevalence of Metal Resistant Genes in Salmonella enterica MDR Plasmids Correlates Severe Toxicities of Water with higher Typhoid AMR
}

Asit Kumar Chakraborty*, PhD and Asim Kumar Roy, BSc

Under Graduate Department of Biotechnology; Oriental Institute of Science \& Technology, Vidyasagar University, Midnapore-720002, West Bengal, India.

Email:chakraakc@gmail.com. Mobile:+917679154141.

\section{Summary}

AMR and drug void have caused huge panic today with few thousand death per year. MDR Typhoid was a serious old disease and caused serious health hazard in humen and animals demanding an update on molecular biology of the status on transferable genetic elements. Rplasmids combined in F'-plasmid and the new MDR conjugative plasmids were shown abundant in Sanmonella ranging 70-440kb with similarities. BlaTEM, blaCTX-M, blaOXA, blaNDM mdr genes were abundant in $>50$ plasmids analyzed and metal resistant gene clusters are predominant in most large plasmids. Among the acetyltransferase all catAl, $a a c A 1$ and $a a c-1 b-c r$ genes were located. Abundant streptomycin phosphotransferases (StrAB) and rarely colistin resistant Mcr-5/9 phosphoethanolamine-lipid A transferase were detected. Altered isomeric dihydropterote synthases (Sul1/2/3) were present giving sulfamethoxazole resistance and $d h f r$ gene frequently associated giving trimethoprim resistance. Metal resistant gene clusters like SilABC (CusABC), PcoAB, RcnA, terABC, and merABCXT etc were found in many Salmonella enterica plasmids. Toxin genes like HipA and virulence genes like spvABD were located in few plasmids increasing virulence and pathogenesis. Drug efflux genes tetA or tetB and $O q x B$, floR, $C m l A$ were frequent where as QepA and EamA genes were rarely seen. Thus, Salmonella metal resistant genes combined with antibiotic resistant genes has tried to overcome the both toxic antibiotics and metalions causing Typhoid AMR. Such acquisition spreads salmoniasis in the live stocks (pig, cow, chicken) where toxic soil and water dominate increasing chance of MDR typhoid in human.

Key words: MDR Typhoid, Metal resistant genes, water toxicity, gut microbiome

Introduction 
Before $1600 \mathrm{~s}$ we have no idea that microorganisms (virus, bacteria, fungus and parasites) cause diseases and we blame ghosts, Sun and Wind. After the discovery of microscope by Anton Van Leeuwenhoek (1670s) and further pioneering works by Edward Jenner (1790s), Lewis Pasteur (1860s) and David Koch (1880s) proved that bacteria and viruses were the culprit of many diseases like TB, Cholera, Typhoid and pox. Edward Jenner (1789) has discovered the Pox vaccination and role of viruses in diseases where antibiotics are useless. Now we control bacteria by inhibiting central dogma processes like replication, transcription and translation as well as cell wall biosynthesis (Chakraborty, 2018). In truth, basic chemical reactions of metabolism of DNA, RNA, protein, sugar, and fat are same among the all life forms but molecular assembly in human 35 trillions cells are different. Thus, understanding the molecular assembly of molecular biological processes are vital to design drugs against deadly pathogens. Biomolecules are nanometer and could be analyzed by assembly $\left(10^{7}-10^{15}\right.$ molecules) using suitable sensitive methods like UV detection of Ethidium bromide stained DNA/RNA, Ninhydrin colour reaction of amino acids, Antigen-Antibody reaction followed by Peroxidase enzyme-mediated colour reaction (ELISA) and FITC-Fuorescence Microscopy methods. Whereas atomic structures of organic molecules were determined by absorption spectra analysis like MASS, NMR, FT-IR and Raman Spectroscopy.

Typhoid Fever is serious disease due to systemic infection of bacterium Salmonella enterica subsp enterica serovar Typhi and now disease has come back due to drug-resistance (Parry et al. 2002; Guerra et al. 2004; Calva et al. 2015; Abraham et al. 2019). Typhoid could be spread by eating or drinking food or water contaminated with the feces of an infected person. Risk factors include poor sanitation and poor hygiene and those travelling in the developing world. Symptoms are high fever accompanied by weakness, abdominal pain, constipation, headaches, and mild vomiting. In 2000, typhoid fever caused an estimated 21.7 million illnesses and 217,000 deaths usually in the children and young adults between 5 and 19 years old mostly from south-central, Southeast Asia and sub-Saharan Africa. Report indicated about 161,000 deaths in 2013 and 149000 in 2015 (https://www.ecdc.europa.eu/en/publicationsdata/typhoid-and-paratyphoid-fever-annual-epidemiological-report-2015). In the United States, about 400 cases occur each year, and $75 \%$ of these are acquired while travelling internationally. According to the most recent estimates by WHO, between 11 and 21 million cases and 128000 to 161000 typhoid-related deaths occur annually worldwide (https://www.who.int/immunization/diseases/typhoid/en/). A typhoid vaccine can prevent about 40 to $90 \%$ of cases during the first two years. An oral live attenuated Ty 21 a vaccine in 
capsule formulation for those over six years of age but injectable Vi polysaccharide vaccine also available. Diagnosis is by either culturing the bacteria or detecting their DNA in the blood, stool, or bone marrow using PCR technique. During prognosis serum AST and ALT may be very high (200-400U/L). The disease was treated with antibiotics such as azithromycin, fluoroquinolones, or third-generation cephalosporins. Salmonella enterica plasmids harbour a composite transposon that can carry multiple resistance genes, including blaTEM-1 (ampicillin resistance), dfrA7 (trimethoprim resistance), sull + sul2 (sulfamethoxazole resistance), catAl (chloramphenicol resistance), and strAB (streptomycin resistance) genes. This composite transposon has also been found integrated into the chromosome in some H58 S. Typhi lineages (Klemm et al. 2018). Many drug resistant determinants are abundant in Salmonella emterica plasmids isolated from different animal sources as well as water and thus AMR is a problem increasing salmoniasis in animal and typhoid in human (Rasheed et al. 2019). Typhoid fever, the causative agent of Salmonella enterica serovar Typhi is spreading in the Asian countries due to acquisition of MDR plasmids from multidrug resistant Escherichia coli and Klebsiella pneumonia (Mandal et al. 2012). However, non-typhoidal MDR Salmonella enterica Serovar Typhimurium were isolated in meat foods (chicken, pork and beef) as well as milk and egg, Such MDR bacteria cause serious diarrhoea and bacteraemia and need hospitalization as happening in the Asia as well as United States due to widespread contamination in livestocks (Sadhanthirakodi et al. 2016). Other than Serovar Typhimurium, Serovar Kentucky, Serovar Idican and Serovar Entiritidis are predominant. Interestingly, we found few very small plasmids those have ether $m d r$ genes or virulence genes or metal resistant genes suggesting toxicities of different kind prevail first generating such plasmids but now such small plasmids combned with F'plasmids and then such Salmonella enterica plasmids further recombined residing in the polluted water resources. 


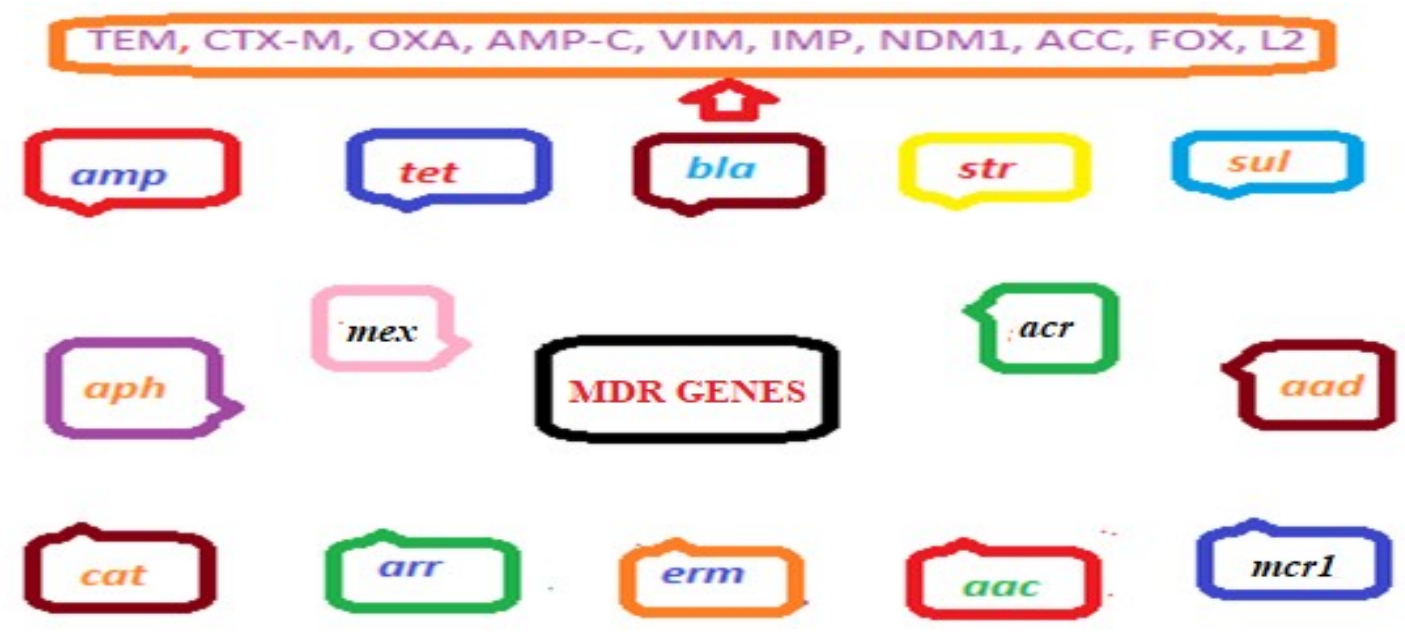

Fig.1. Different types of $m d r$ genes reported in Enterobacteriaceae plasmids.

There are many mdr genes located in Enterobacteriaceae plasmid since 1950s as shown in Figure-1 (Chakraborty, 2018). First, amp and tet genes were sequenced in pBR322 in 1965 and since the application of colour di-deoxy DNA sequencing, millions plasmid sequences were deposited in GenBank. Amp gene was renamed as bla or beta-lactamse and now 20 different beta-lactamases classes were reported with million of mutated isomers and most importantly ESBL and MBL multiple isomers were located in MDR single conjugative plasmid with size $>100 \mathrm{~kb}$ (Chakraborty, 2017). Similarly, tetAB, acrAB, mexAB/CD/EF, bcr, mor types MFS and RND drug efflux genes were reported in E. coli, P. aeruginosa, $K$. pneumonia as well as $S$. enterica plasmids. Many metal efflux genes (silABC, merB, rcnA) and metal binding genes (telC, silz) were reported in MDR plasmids. Abundance of metal resistant gene cluster in association of $m d r$ genes suggested that metal toxicity in water might be precede the antibiotic toxicity. We will describe here the different types of those genes in Salmonella plasmids causing recent outbreaks of salmoniasis in animals and typhoid in human.

\section{Material \& Methods}

We got the plasmid sequences from NCBI Nucleotide GenBank Database by typing "Salmonella" and "plasmid". We retrieve the each sequence and searched for mdr genes, drug efflux genes, toxin genes, and virulence genes. BLAST search was performed to get relation among the peers (www.ncbi.nlm.nih.gov/blast). Plasmids were divided into small (3$15 \mathrm{~kb})$, medium $(15-49 \mathrm{~kb})$, large $(50-100 \mathrm{~kb})$ and very large $(>100 \mathrm{~kb})$ and plasmid may have 
mdr gene or no madr gene but virulence genes. Similarly, few plasmids have both metal resistant gene and $m d r$ genes but $m d r$ gene may not be found in few plasmid. Interestingly, such review was absent in the pubmed.

Result

Table-1 showed the overall description of the plasmids describing $m d r$ genes, drug efflux genes, metal resistant genes as well as other genes involved in the Salmonella pathogenesis. Few plasmids were found small $<50 \mathrm{~kb}$ and large plasmids were $200-400 \mathrm{~kb}$ in size and were sequenced between 2015-2019. Plasmids pHK0653, pSTm-A54650, pRH-1238, pHXY0908, P87912 and pF8475 contained nine mdr genes and few drug efflux genes. TetA drug efflux genes located in most plasmids irrespective of sizes as also we found strAB streptomycin phosphotransferases where as BlaTEM was more frequent than blaCTX-M, blaOXA1 or blaNDM1 where as blaOXA23/48/58 were not detected. Sul1 isomer of dihydropterote synthase was abundant than Sul2 and Sul3 isomers (Roschanski et al. 2014). Metal resistant genes were found in many large MDR conjugative plasmids like p8025 (accession no. KP899803), pSTM6-275 (accession no. CP019647), pSH111_227 (accession no. JN983042) and pF8475 (accession no. KP899804). Mercury resistant locus was found in plasmid pF8475 (accession no. KP899804) in association with sul1/2, strA, blaTEM, dhfr, aacC2 and mphA mdr genes (Zhang et al. 2018). Plasmids pHK0653, pFORC19 and pSTM6-275 have HipA toxin gens where as plasmid pSE81-1706 and pFORC19 have spvA/B/D virulence genes associated with cat, blaTEM and aph $m d r$ genes. The plasmid pOU1113 (accession no. AY517905) has virulence genes spvD/ trbD but no mdr gene where as in plasmid pSTU2881(accession no. CP004058), $s p v A / s p v B$ virulence genes were located in association with sull, aad, aac3', dhfr and cmlA2 mdr genes giving resistant to sulfamethoxazole, streptomycin, gentamycin, kanamycin, trimethoprim and chloramphenicol. However, plasmid pA3T (accession no. KX421096) has no beta-lactamase or acetyl/phospho - transferases but accumulated OqxA and OqxB RND-type drug efflux proteins which form tripartite protein complex with oprM-type membrane protein to exclude variety of drugs. The plasmid pSH696_135 (accession no. JN983048) has many transcription factors like merD, tetR, entR and flhC regulating $m d r$ genes like blaCMY, sul1, strA/B, blaTEM and aadA. Silver efflux proteins silABC (ARX76242/3/5) were located in small Salmonella plasmid pSH-01 (43kb; accession no. KY486279) and such locus was also found in many large MDR plasmids like pYU39_IncA/C (156kb; accession no. 
CP011429) in association with multi-drug efflux protein acrEF (protein ids. AKH10329/30), a homologue of acrAB acridine drug efflux proteins and streptomycin inactivating proteins strAB (protein ids. AKH10232/3). The Salmonella 249kb plasmids pHXY0908 (accession no. KM877269) and p15-0756 (accession no. CP039857) are similar size but pHXY0908 has multiple $m d r$ genes (aph, sul1, aad, sul2, aac3', aac6'-1b-cr, cat blaOXA, arr3) with only tellurium resistant locus where as the other has multiple metal resistant genes locus like copper resistant locus PcoECBA (nt. 68858-74109) and silver resistant locus silPABCRSE (nt. 75407-87859) as well as tellurium resistant locus terWZABCDF (nt. 24736-30955). Abundance of metal binding proteins and metal efflux proteins in Salmonella plasmids indicated that such MDR bacteria suffered in the environmental water and had forced to accumulate multiple metal resistant locus where as in the human host such bacteria may lost few metal resistant genes acquiring many antibiotic resistant genes (Kaldhone et al. 2019). A similar huge accumulation of silver, copper, mercury and tellurium resistant genes were seen in large plasmid pRH-R27 (accession no. LN555650) where very rare nical-cobult specific efflux protein renA was also present (protein id. CED95467) in association with blaVIM, aac6'-1b, sull and strAB mdr genes (Kaldhone et al.2019). Plasmid pCFSA300-1 appeared very similar in plasmid pHK0653 with respect to $m d r$ genes (dhfr, sul, blaOXA1, aac3', ANT3”) but citrate lyase, Adenine-Guanine phosphoribosyl transferase and carbomoyl phosphate synthase were inserted at tellurium resistant locus. Interestingly, a very small 14kb Salmonella typhimurium plasmid pMG101 (accession no. AF067954) had all silver resistant genes but no other antibiotic resistant genes indicating metal resistance was primitive and likely occurred during European industry development between 1760-1850s where as $m d r$ genes were created after 1940 (Gupta et al. 1999; Chakraborty, 2019). We also found a medium plasmid pSA20044414 (accession no. CP030210) with many arsenic and copper resistant genes in association of Tra conjugative proteins but no $m d r$ gene was detected indicating F'-plasmid may be combined with small metal resistant plasmids like pMG101 with silver resistant locus and then small R-plasmids like pSc101 and pMB were combined to originate modern day large MDR conjugative plasmids like p87912 (accession no. CP041180) which contained sixteen mdr genes and two drug efflux genes like oqxA/B (Chakraborty, 2018). Never the less, WGS of Salmonella (accession nos. CP000026, AE014613) indicated that metal resistant locus were also frequently associated with Salmonella genome (Calva et al. 2015). Mcr-9 enzyme (protein id. ANV19589) was detected in plasmid p09-036813-1A_261 (261kb; accession no. CP016526) in association of aph6-Id, aph3”, dhfr, aac3”, aacA4 and tellurium, mercury and arsenic metal resistant genes. Such 
mutant mor-1 was detected in many S. enterica isolates (Lozano-Leon et al. 2019) giving colistin resistance and more deadly blaNDM-1 also was detected giving imipenem resistance (Banerjee et al. 2018).Salmonella enterica serovar Seftenberg pNDM-SAL plasmid (accession no. KP742988) has both cephamycinase and carbapenemase and thus highly resistant to all beta-lactams and similar Salmonella plasmids pHS36-NDM (accession no. KU726616) and pRH-1238(accession no. KR091911) ware sequenced (Huang et al. 2013; Villa et al. 2015).

\begin{tabular}{|c|c|c|c|c|c|}
\hline Plasmid name & $\begin{array}{l}\text { Size } \\
\text { in } \mathrm{kb}\end{array}$ & $\begin{array}{l}\text { Accession } \\
\text { number }\end{array}$ & Mdr genes & $\begin{array}{l}\text { Drug \& Metal } \\
\text { Efflux genes }\end{array}$ & $\begin{array}{l}\text { Virulence } \\
\text { genes }\end{array}$ \\
\hline pGMI14-002_1 & 444 & CP028197 & $\begin{array}{l}\text { blaSHV12, aac6'-II, aac3-II, } \\
\text { arr3, mcr1, dhfr, aph6-Id }\end{array}$ & merA, terCZ, renA & HipA \\
\hline pIMP4-SEM1 & 340 & KX810825 & blaTEM, catB, dhfr. strBA & $\begin{array}{l}\text { tetA, } \\
\text { terFECBAZW, } \\
\text { terYX }\end{array}$ & HipA \\
\hline P8025 & 311 & KP899803 & aadA1, dhfr, sul1 & $\begin{array}{l}\text { tetA, acrAB, merA, } \\
\text { arsB }\end{array}$ & - \\
\hline pSTm-A54650 & 309 & LK056646 & $\begin{array}{l}\text { dhfr, blaOXA, catB3, tuniR, } \\
\text { blaCTX-M15, blaTEM, strAB, } \\
\text { sul1, aadA1, catA1 }\end{array}$ & $\begin{array}{l}\text { tetA, qnrS1, pcoE, } \\
\text { rcnA, arsB, merB }\end{array}$ & $\begin{array}{l}\text { TniB } \quad \mathrm{dcm} \\
\text { telA }\end{array}$ \\
\hline pIncH12 & 300 & LN794248 & $\begin{array}{l}\text { Sul2, strAB, blaTEM, dhfr, } \\
\text { blaOXA30, aadA1 }\end{array}$ & $\begin{array}{l}\text { terXYABDEF, } \\
\text { renA, arsB }\end{array}$ & $\begin{array}{l}\text { vwfAB, } \\
\text { pvuIIM }\end{array}$ \\
\hline pRH-R27 & 299 & LN555650 & $\begin{array}{l}\text { Sul1, strAB, aac6'-1b, } \\
\text { blaVIM1, , aadA1 }\end{array}$ & $\begin{array}{l}\text { TerABC, arsB, } \\
\text { renA, Pcos, silAB, } \\
\text { merTC }\end{array}$ & Dcm, dam \\
\hline pFSAN096147 & 291 & СР044256 & blaTEM, qnrS1, blaLAP2, & $\begin{array}{l}\text { tetA, } \quad \text { tetB, } \\
\text { terXBCEF, } \operatorname{rcnA}, \\
\text { sliCBA, } \quad \text { cusF, } \\
\text { merT, Hg R, arsHB }\end{array}$ & HipA, dcm \\
\hline P280_12888 & 276 & CP045449 & $\begin{array}{l}\text { Aac3-IV, aph4-Ia, sul1, } \\
\text { ANT3"-Ia, dhfr }\end{array}$ & $\begin{array}{l}\text { terXWZABCDsilE } \\
\text { SCBAP, PcoAB, } \\
\text { merT }\end{array}$ & $\mathrm{dcm}$ \\
\hline pSTM6-275 & 275 & CP019647 & StrA, tet, blaTEM, aadA2, dhfr & $\begin{array}{l}\text { EamA, } \\
\text { Sil,Ter, PcoA }\end{array}$ & HipA \\
\hline pSa27-Tc-CIP & 270 & MH884653 & blaTEM1, tetC, dhfr, ble & silEABCRS & virB, $\mathrm{dcm}$ \\
\hline $\begin{array}{l}\text { p09-036813- } \\
1 \text { A_261 }\end{array}$ & 261 & CP016526 & $\begin{array}{l}\text { Aph6'-1a, aph3”, dhfr, aac3', } \\
\text { aacA4, mcr1 }\end{array}$ & $\begin{array}{l}\text { terWZABCF } \\
\text { MerA, merT arsBA, } \\
\text { renA }\end{array}$ & hipA, dcm \\
\hline $\mathrm{pA3T}$ & 253 & KX421096 & $\begin{array}{l}\text { Ble, sul1, fosA, blaCTX-M-14, } \\
\text { aac3-IV }\end{array}$ & $\mathrm{OqxB} / \mathrm{A}$, terB & Dam, dcm \\
\hline P15-0756 & 249 & CP039857 & $\begin{array}{l}\text { lnuF, ANT3", tetM, tetA, } \\
\text { EamA }\end{array}$ & $\begin{array}{l}\text { terWZABCDF } \\
\text { PcoECBA } \\
\text { silPABCRSE }\end{array}$ & hipA. dcm \\
\hline pHXY0908 & 249 & KM877269 & $\begin{array}{l}\text { aph, sul1, aad, sul2, aac3', } \\
\text { aac6'-1b-cr, cat blaOXA, arr3, }\end{array}$ & $\begin{array}{l}\text { oqxB/A, cml, floR, } \\
\text { terE/D, terC } / Y / Z\end{array}$ & HipA \\
\hline pHK0653 & 245 & KT334335 & $\begin{array}{l}\text { Dhfr, sul, aad, hph, aac, } \\
\text { blaOXA1, cat, arr3 }\end{array}$ & $\mathrm{OqxB}, \mathrm{CmlA} 2$, terF & $\begin{array}{l}\text { HipA, } \\
\text { Collicin1b }\end{array}$ \\
\hline P16-6773 & 245 & CP039861 & Aph3'-I, ANT3"-I, LnuF, sul3 & $\begin{array}{ll}\text { floR, } & \text { terBCD, } \\
\text { terAZ }\end{array}$ & HipA, dcm \\
\hline pJXP9 & 244.7 & MK673549 & $\begin{array}{l}\text { Dhfr, aph3", estX, aad, } \\
\text { blaCTX-M14, fosA }\end{array}$ & $\begin{array}{l}\text { floR, } \\
\text { terFEDCBA, } \\
\text { terZY }{ }_{1} \mathrm{XY}_{2}\end{array}$ & $\mathrm{dcm}$ \\
\hline pSE81-1706 & 244 & CP018656 & Cat, blaTEM, aph & tetA & spvA/B/D \\
\hline P87912 & 236 & CP041180 & $\begin{array}{l}\text { Acc6'-1b-cr, blaOXA1, catB3, } \\
\text { arr3, sul1/2 blaCTX-M65, }\end{array}$ & oqxAB & rmtB1 \\
\hline
\end{tabular}




\begin{tabular}{|c|c|c|c|c|c|}
\hline & & & $\begin{array}{l}\text { fosA3, blaTEM1, aph3"-1b, } \\
\text { aph6-Id, ANT3"-I, dhfr, ble, } \\
\text { aph4-I, mph2, }\end{array}$ & & \\
\hline pSH111 227 & 227 & JN983042 & strA/B, sph & TetA, terF, cusC & Dam, dcm \\
\hline P220k & 220 & CP025340 & $\begin{array}{l}\text { ANT3”, mphA2', aac3-IV, } \\
\text { aph4-Ia, }\end{array}$ & $\begin{array}{l}\text { oqxAB, } \quad \text { cmlA1 } \\
\text { terZXABCDF, } \\
\text { cusAP, PcoADS, } \\
\text { floR }\end{array}$ & dam \\
\hline pHCM1 & 218 & AL513383 & blaTEM, sul1, strA/B & tetA & mucB \\
\hline pCFSA300-1 & 209 & CP033382 & $\begin{array}{l}\text { Sul2, dhfr, aph3"-1b, blaOXA1, } \\
\text { ANT3"-Ia }\end{array}$ & $\begin{array}{l}\text { OqxAB,terXW, } \\
\text { terZABCDF }\end{array}$ & $\begin{array}{l}\text { HipA,Dcm, } \\
\text { ArmA }\end{array}$ \\
\hline $\mathrm{pF} 8475$ & 210 & KP899804 & $\begin{array}{l}\text { Sul1/2, strA, blaTEM, dhfr, } \\
\text { aacC2, mphA }\end{array}$ & tetB, $\operatorname{mer} \mathrm{A} / \mathrm{C} / \mathrm{P} / \mathrm{T}$ & $\begin{array}{l}\text { Dem, dam, } \\
\text { trhU }\end{array}$ \\
\hline P109/9 & 207 & KP899805 & Cat, blaTEM, sul2, aph3' & tetB, merA & - \\
\hline pUO-STmRV1 & 197 & CP018220 & $\begin{array}{l}\text { Aph3", aac3, ANT3", sul1, } \\
\text { blaCTX-M }\end{array}$ & $\begin{array}{l}\text { cmlA1, } \mathrm{CuS} / \mathrm{C} \text {, } \\
\text { MerC/T, ArsH, }\end{array}$ & $\begin{array}{l}\text { SpvA. SpvB/ } \\
\text { D }\end{array}$ \\
\hline pB71 & 190 & KP899806 & aadA1, sul1 & tetB & cobZ, dcm \\
\hline pRH-1238 & 188 & KR091911 & $\begin{array}{l}\text { mphA, sul1, aadA5, dgfr7, } \\
\text { blaNDM1, blaCMY16, strAB, } \\
\text { sul2 }\end{array}$ & tet $\mathrm{A}, \mathrm{chrB}$ & \\
\hline pRH-1238 & 187 & KR091911 & $\begin{array}{l}\text { Sul1/2, aad, dhfr, aac6', aph, } \\
\text { mel, blaNDM, strB/A, } \\
\text { blaCMY-16 }\end{array}$ & tetA, floR, mel & Rhs1, vWFS \\
\hline pYU39_IncA/C & 156 & CP011429 & strA/B, sul2,, ble & $\begin{array}{l}\text { acrEF, } \\
\text { silPACSER }\end{array}$ & Rhs, dcm \\
\hline pSTU288-1 & 148 & CP004058 & Sul1, aad, aac, dhfr & $\mathrm{CmlA}$ & spvD, trbD \\
\hline pNDM-SAL & 146 & KP742988 & blaCMY4, blaNDM1 & Dam, dcm & Vwf, rhs \\
\hline pHS36-NDM & 138 & KU726616 & $\begin{array}{l}\text { blaNDM1, sul1, } \\
\text { blaAmpC, ble }\end{array}$ & CobS & Vwf, \\
\hline pSH696_135 & 135 & JN983048 & $\begin{array}{l}\text { Sull, strA/B, } \\
\text { blaTEM, aadA }\end{array}$ & $\begin{array}{l}\text { floR } \\
\text { merA/D/T }\end{array}$ & - \\
\hline P9134 & 134 & KF705205 & Hpt, blaTEM & tetA & pilQ \\
\hline pSa18934b & 133 & JF274992 & aph & tetA, merEA & spvABCD \\
\hline pST3553 & 132 & AP014566 & blaTEM, aadA, sull & tetA & - \\
\hline pGDD25-16 & 130 & MH316136 & blaCTX-M-27, dhfr & QepA & Dcm, rmtB \\
\hline R64 & 121 & AP005147 & strA/B & tet $\mathrm{A}, \operatorname{arsB}$ & pilQ \\
\hline pFORC19 & 117 & CP012397 & $\begin{array}{l}\text { Dhfr, strA/B, aph, aac3', } \\
\text { TunicaR }\end{array}$ & tet $\mathrm{A}$, merA/C & $\begin{array}{l}\mathrm{HipA}, \\
\text { spvA/B/D }\end{array}$ \\
\hline pST1007-1B & 109 & MH626558 & Dhfr, aad & $\begin{array}{l}\text { tetB, cml, EmrE, } \\
\text { merAT }\end{array}$ & - \\
\hline pSH1148_107 & 107 & JN983049 & Sul1, aacC1, aadA1 & & Colicin1b \\
\hline P16-6397 & 94 & CP040322 & No mdr gene & TraI & spvABC \\
\hline pSA20044414 & 93 & CP030210 & No mdr gene & $\begin{array}{l}\text { ArsAB, } \\
\text { CusA }\end{array}$ & - \\
\hline pST1007-1D & 92 & MH648141 & blaTEM, strA, sul1 & merA & \\
\hline pSA20070548 & 84 & CP040652 & blaTEM, aadA2, ble & $\begin{array}{l}\text { tetM, SilCB silA/P, } \\
\text { merT/C }\end{array}$ & dam \\
\hline pOU1113 & 80 & AY517905 & No mdr gene & - & spvAB \\
\hline pQJDSal1 & 67 & CP022964 & Sul2, blaTEM1 & $\operatorname{arsABCH}$ & virB \\
\hline pSH-01 & 43 & KY486279 & QnrS1, tetA & $\begin{array}{l}\mathrm{silP} / \mathrm{A} / \mathrm{B} / \mathrm{C} / \mathrm{R} / \mathrm{E}, \\
\mathrm{CusF} / \mathrm{S}\end{array}$ & - \\
\hline pSE12-02541 & 17 & KY807920 & blaTEM1, mcr-5 & - & - \\
\hline pMG101 & 14 & AF067954 & No mdr gene & silESRCBAP & - \\
\hline pSE13-SA01718 & 12 & KY807921 & Mcr-5 & chrB & \\
\hline pNL2001 & 4 & D14490 & No mdr gene & - & spvABC \\
\hline
\end{tabular}

Table-1 Note: BlaTEM is similar to amp gene of pBR322 and it lyses benzyl penicillin and ampicillin but not cefotaxime and oxacillin. TetA and TetB enzymes are $\sim 400$ aa transmembrane protein and remove tetracycline from bacterial cytoplasm giving tetracycline resistance. Such gene (tetC) was discovered first in plasmid pBR322. StrA and StrB phosphorylates streptomycin and phosphorylated streptomycin could not able to bind ribosome giving resistance. Other phosphotransferases (aph) are known to give gentamycin and kanamycin resistance. Cat enzyme acetylates chloramphenicol and 
acetylated chloramphenicol did not bind ribosome. AacC1 and aacAl types acetyltransferases are abundant in plasmids causing aminoglycosode resistance. Hpt is hygromycin phosphotransferase and Arr3 is refampicin phosphotransferase. Dhfr enzyme gave resistance to trimethoprim and sul1/2/3 are altered dihydropterote synthase enzyme giving sulphonamide resistance. spvB is Actin ADP ribosyl transferase and inactivates muscle function. Dcm is cytosine MTase and Dam is adenine methyltransferase where as $\mathrm{rmtB}$ is $16 \mathrm{~S}$ rRNA methyltransferase giving drug resistance altering rRNA structure in the ribosome. HipA is a serine-threonine protein kinase that likely phosphorylates tRNA(Glu) synthetase (GltX). CmlA is chloramphenicol efflux membrane protein and acrAB is RND-MFS drug efflux proteins and similar to OqxAB. Colicin resistance is due to a colcin $1 \mathrm{~b}$ transporter and colicin drug bind to cell membrane inhibiting mureib biosynthesis in bacteria. QepA drug efflux protein located in Salmonella plasmid pGDD25-16 gives floroquinolone resistance as also possible for the presence of aac6'-1b-cr protein in plasmid pHXY0908 due to N-acetylation of ciprofloxacin.

Beta-lactamases in Salmonella plasmids were analyzed and major isomer was blaTEM-1 (protein ids. AYM49671, QDG23938, QCW01640, CDR86458, CEO37446 and QEX03237) and no mutations were found (figure-2A). Similarly, no mutation was detected in streptomycin phosphotrnsferases strA (figure-2B) and strB (figure-2C). In plasmid pSTmA54650 (accession no. LK056646) blaOXA-1 was found in association of blaTEM-1 similar to blaCTX-M-65 in plasmid p87912 (accession no. CP041180) and pUo-STmRV1 (accession no.CP018220). TetA tetracycline efflux and tetracycline binding protein tetM were located in plasmid p15-6756 (accession no. CP039857) but no beta-lactamase gene was located but many metal resistant genes like ter locus, sil locus and PcoECBA copper resistant genes. In a pan drug resistant S. enterica, multiple adenyltransferases (protein ids. ALI92932, ALI92934) and acetyltransferases (protein ids. ALI92932, ALI92954) and dihydropteroate synthases (ALI92929, ALI92944, ALI92959) were detected in its plasmid pHK0653 (accession no. KT334335).

Tetracycline resistant drug efflux proteins tetA and tetB have 60\% homology (Figure-3D) but no mutations was detected among the tetA proteins (figure-3A) or tetB proteins (figure-3B) but no mutation was detected in the RND drug efflux protein OpxB (figure-3C). Chloramphenicol/ florfenicol efflux MFS transporter (FloR) was found in many plasmids and few mutations were present (figure-4). Salmonella enterica fluoroquinolone MFS drug efflux transporter QepA (protein id. AWW22306, plasmid pGDD25-21) and macrolide MFS efflux protein (Msr-family ABC-F type like Mel; protein id. AKN19296, plasmid pHXY0908) and chloramphenicol drug efflux protein (AXY98896, plasmid pST1007-1B; Bcr-cflA family) were rarely detected. 
In Salmonella plasmids, arsB (A) and arsC (B) arsenic metal efflux genes were found and mutations were detected (Figure-5A/B) as well as silver efflux genes like silABC (Figure-6). Mercuric reductase (merA) and multi-copper oxidase (PcoA) were abundant and many mutations were observed in PcoA but merA was conserved among the plasmids (Figure-7). $\mathrm{RcnA} \mathrm{Ni++/Co++} \mathrm{transporters} \mathrm{of} \mathrm{Salmonella} \mathrm{enterica} \mathrm{plasmids} \mathrm{(protein} \mathrm{ids.} \mathrm{AVS55158,}$ AZM67488, QEX03304, CEO37522, CDR86475) were identical as also found in other bacterial species like E. coli, E. cloacae, S. enterica, K. oxytoca, S. marcessens but I327F mutation in $C$. fruendii where as Other Klebsiella species like K. pneumoniae, $K$. aerogenes and $K$. quasipneumoniae have more mutated forms (a new lineage) of RenA transporter (figure-8). Further in K. quasipneumoniae plasmid-mediated RcnA four amino acids (GHDH) insertion was detected at 234 amino acid position where as a four amino acid deletion (AEHD) at amino acid position 230 of RenA of Klebsiella aerogenes.

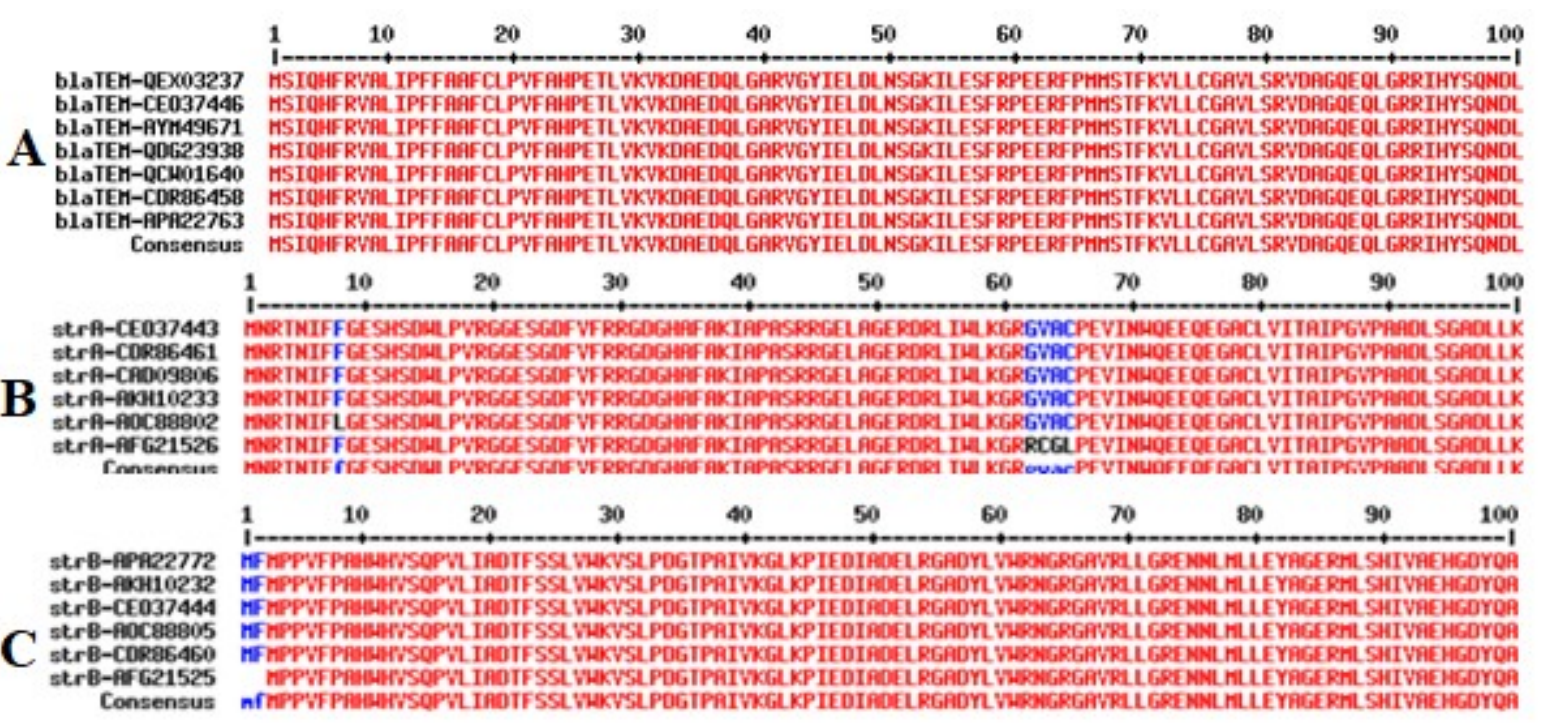

Fig.2. Multialign of class A Beta-lactamases and streptomycin 3'/6' phosphotransferases. Part of the aligns were shown here, blaTEM-1 (A), StrA (B) and StrB (C). 
tetA-BAP 10655 tetA-ASF 62691

A tetA-AHC55487 tetA-AKJ19550

tet $B-B A B 91576$ tetB-AKJ20239

B tetB-AKJ20055

OCXXB-AOR05930 OCXB-AKG90132 OqXB-qgq84092

C OqXB-QPG24035 OcxB-ALI 92905 vhsndvt ahygillalyalmqfacapvlgalsdrfgrrpvllvslagaavdyaimatapf 95 vhsndvt ahygillalyalmqfacapvlgalsdrfgrrpvllvslagaavdyaimatapf 95 vhsndvt ahygillalyalmqfacapvlgalsdrfgrrpvllvslagaavdyaimatapf 120 vhsndvt ahygillalyalmqfacapvlgalsdrfgrrpvllvslagaavdyaimatapf 120

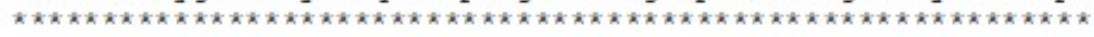

mnsstkialvitlldamgiglimpvlptllrefiasedianhfgvllalyalmqvifapw 60 mnsstkialvit lldamgiglimpvlptllrefiasedianhfgvllalyalmqvi fapw 60 mnsstkialvitlldamgiglimpvlptllrefiasedianhfgvllalyalmqvifapw 60 mnsstkialvitlldamgiglimpvlptllrefiasedianhfgvllalyalmgvi fapw 60

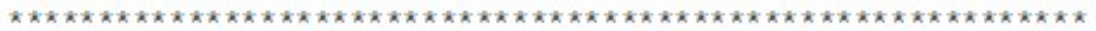

mdfsrffidrpifaavlsilifitgliaipllpvseypdvvppsvqvraeypganpkvia 60 mofsrffidrpifaavlsilifitgliaipllpvseypdvvppsvqvraeypganpkvia 60 mdfsrffidrpifaavlsilifitgliaipllpvseypdvvppsvqvraeypganpkvia 60 mofsrffidrpifaavlsilifitgliaipllpvseypdvvppsvqvraeypganpkvia 60 mdfsrffidrpifaavlsilifitgliaipllpvseypdvvppsvqvraeypganpkvia 60

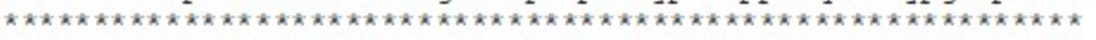

BAP 10655 GALSDRFGRRPVLLVSLAGAAVDYATMATAPFLWVLYIGRIVAGITGATGAVAGAYIADI
$G+$ SDRFGRRDVLI + SI GA $++\mathrm{DY}++\mathrm{A}+$ LW+LY + GR +++ GITGATGAVA + IAD

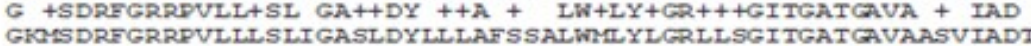

AKJ20239

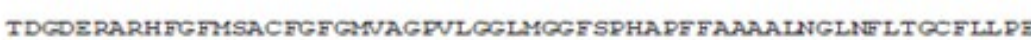

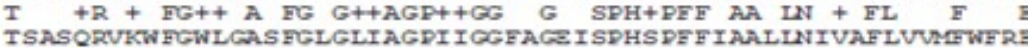

D AKJ20239 SHRGERRDLRREALNDIASFPWARCIIVVARIMAVF FIMOLVQOVDARIWUI FGEDRFHW $+\quad+++\quad+\quad++F \quad Q L+C Q+P A+W V+F \quad \mathrm{E}+R F$

BAD 10655

AKJ20239 TKOTRDIIDTEVGVICSNSUYITLFKMMPILII IYFSAQLICOI PATUWUL FIENREGW

DATIIGISLAAFGILHSLAMITGPVARRLERRALILMIADGTGYIILAFATRGMA ++ +G SLA G+LHS+ $Q A+G+A+G E+A++I G I A D++L A F+G N+$

BAP10655

AKJ20239

BAP 10655

AKJ20239

BAD10655

AKJ20239

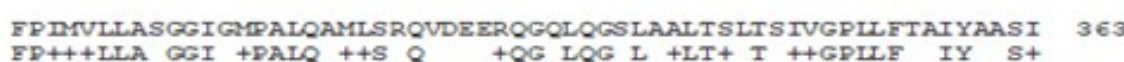

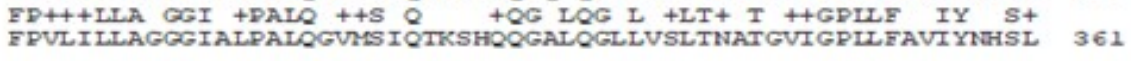

TIWANGWAWIAGAALYLLCL 382

W+GW WI G A Y + +
IWDGWIWIIGIAFYCIII 380

Fig.3. Multialign analysis of plasmid-mediated TetA (A), tetB (B) tetracycline drug efflux proteins and OqxB (C) drug efflux protein of Salmonella enterica. Amino acids 201-240 and 404-420 have difference between tetA and tetB as demonstrated by BLAST Seq-2 align (D). No mutations among tetA, tetB and OqxB were detected in Salmonella plasmids. 


\begin{tabular}{|c|c|c|c|c|c|c|c|c|c|c|}
\hline \multirow{3}{*}{$\begin{array}{r}\text { FloR-AFG21521 } \\
\text { FloR-AXA99524 } \\
\text { FloR-QCL03276 } \\
\text { FloR-QEQ67123 } \\
\text { FloR-AKN19379 } \\
\text { Consensus }\end{array}$} & 1 & 10 & 20 & 30 & 40 & 50 & 60 & 70 & 80 & 0 \\
\hline & $\begin{array}{l}\text { ITT } \\
\text { ITI } \\
\text { IT }\end{array}$ & 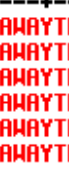 & $\begin{array}{l}\mathrm{MAP} \\
\mathrm{LAP}^{\mathrm{MAP}} \\
\mathrm{MAP}^{2}\end{array}$ & LAMD & $\begin{array}{l}\text { PAMP } \\
\text { PAMPP } \\
\text { PAMP } \\
\text { PAMP }\end{array}$ & $\begin{array}{l}\text { TPAII } \\
\text { TPAMI } \\
\text { TPAMI } \\
\text { TPAMI } \\
\text { TPAMI }\end{array}$ & FHWH & VIFG & $\begin{array}{l}\text { GRRP } \\
\text { GRRP } \\
\text { GRRP } \\
\text { GRRP }\end{array}$ & 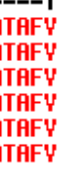 \\
\hline & 91 & 100 & 110 & 120 & 130 & 140 & 150 & 160 & 170 & 180 \\
\hline $\begin{array}{l}\text { loR-AFG21521 } \\
\text { loR-AXK99524 } \\
\text { loR-QCL03276 } \\
\text { loR-QEQ67123 } \\
\text { loR-AKN19379 } \\
\text { Consensus }\end{array}$ & T & & -4 & FHL & D? & YI & AH & r & 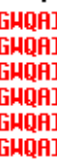 & 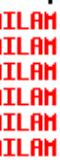 \\
\hline
\end{tabular}

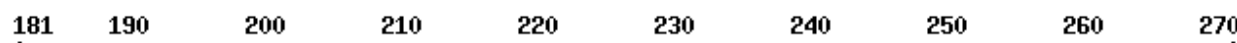

$181 \quad 190 \quad 200 \quad 210 \quad 220 \quad 230 \quad 240 \quad 250 \quad 260 \quad 270$ FloR-AFG21521 LALLNAGFRLHETRPLDQYKTRRSYLPFASPAFHYYTYGFSAGHG FloR-AXA99524 LALLNAGFRHHETRPLDQYKTRRSYLPIFASPAFHYYTYGFSAGMGTYFYFFSTAPRYLIGQAEYSEIGFSFAFATYAL YMIYTTRFAKS FloR-QCL03276 LALLHAGFRHHETRPLDQYKTRRSYLPIFASPAFHYYTGGSAGHGTYFYFFSTAPRYLIGQAEYSEIGFSFFFATYAL YHIYTTRFAKS FloR-QEQ67123 LALLHAGFRLHETRPLDQYKTRRSYLPIFASPAFHYYTYGFSAGMGTYFYFFSTATRYLIGQAEYSEIGFSFAFATYALYMIYTARFAKS FloR-AKN19379 LALLNAGFRHHETRPLDQYKTRRSYLPIFASPAFHYYTYGFSAGMGTFFYFFSTAPRYLIGQAEYSEIGFSFAFATYAL UMIYTTRFAKS Consensus LALLNAGFRHHETRPLDQYKTRRSYLPIFASPAFHYYTYGFSAGHGT\%FYFFSTAPRYLIGQAEYSEIGFSFAFATYAL YHIYTERFAKS

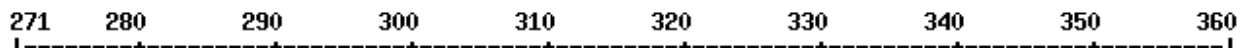

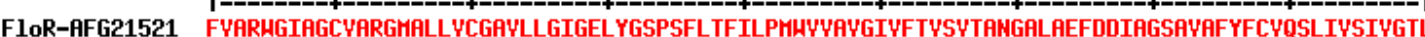

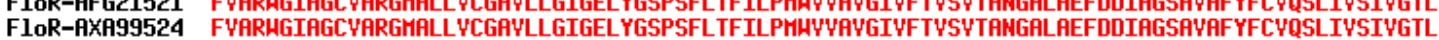

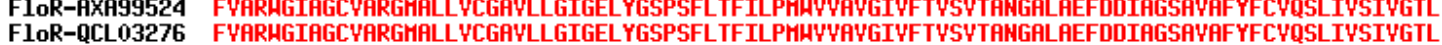

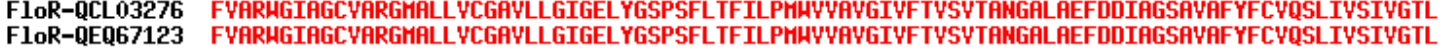
FloR-AKN19379 FYARHGIAGCYARGHALLYCGAYLLGIGELYGSPSFLTFILPMHYYAYGIYFTYSYTANGALAEFDDIAGSAYAFYFCYQSLIYSIYGTL Consensus FYARHGIAGCYARGMLLL YCGAYLLGIGELYGSPFLTFILPMHYAYGIYFTYSYTANGALAEFDDIAGSAYAFYFCYQSLIYSIYGTL

\begin{tabular}{|c|c|}
\hline 370 & 380 \\
\hline
\end{tabular}

\begin{tabular}{|c|c|}
\hline FloR-AFG21521 & AYALLNGDTALPYICYATAMAYLYSLGLYLLRLRGAATEKSPYY \\
\hline FloR-AXA99524 & AYALLNDDTALPYICYATAMAYLYSLGLYLLRLRGFATEKSPYY \\
\hline FloR-QCL03276 & AYALLNRDTALPYICYATAMAYLYSLGLYLLRLRGHATEKSPYY \\
\hline FloR-QEQ67123 & AYALLNGDTALPYICYATAMAYLYSLGLVLLRLRGAATEKSPYY \\
\hline oR-AKN19379 & AYALLNGDTALPYICYATAMAYLYSLGLYLLRLRGAATEK \\
\hline Consensus & AYALLNgDTALPYICYATAMAYLYSLGLYLLRLRGAHTEKsPvv \\
\hline
\end{tabular}

Fig.4. Multialign sequence analysis of plasmid-associated FloR protein (chloramphenicol/ florfenicol efflux MFS transporter) showing mutations. FloR protein AFG21596 of $S$. enterica serovar Heidelburg has more mutations. Other chloramphenicol MFS drug efflux transporter CmlA family has only 25\% sequence similarity to FloR (protein ids. ALI92933 and AXH26379). 


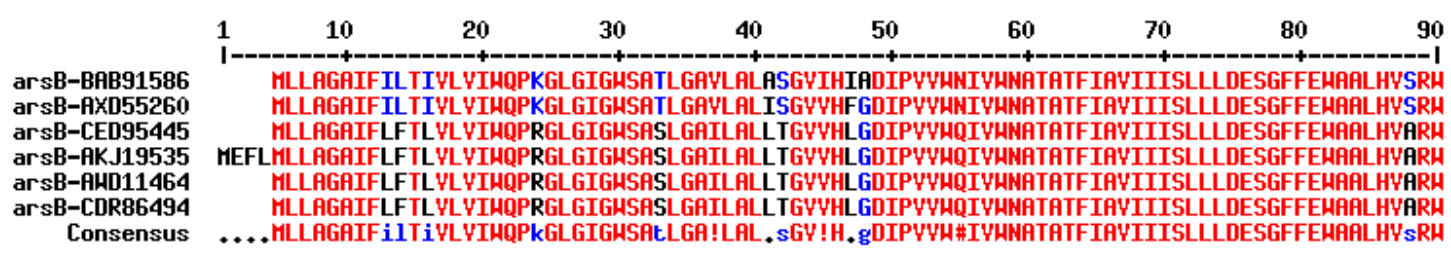

100

110

120

130

140

150

160

170

180

arsB-BAB91586 arsB-AXD55260 arsB-CED95445 arsB-AKJ19535 arsB-FHD11464

GNGRGRLLFTYTYLLGARYARLFANDGAFLILTPIYTAMLLALGFSKSTTLAFYMAAGFIADTASLPLIYSNL UNTYSADFFKLGFTEYA GNGRGRLLFTYIYLLGAAYAALFANDGAFLILTPIYIAMLLALGFSKGTTLAFYMAAGFIADTASLPLIYSNL YNIYSADFFGLGFTEYA GNGRGRLLFTHIYLLGAMYAFLFANDGAFLILTPIYIAMLLALGFSRGATLAFIMAFGFIADTASLPLIYSNL YNIYSADFFKLGFSEYA GNGRGRLLFTHIYLLGAMYAALFANDGAALILTPIVIAMLLALGFSRGATLAFIMAAGFIADTASLPLIYSNL YNIYSADFFKLGFSEYA GNGRGRLLFTHIYLLGAMYAFLFANDGAFLILTPIVIAMLLALGFSRGATLAFIMAFGFIADTASLPLIYSNL YNIYSADFFKLGFSEYA GNGRGRLLFTHIYLLGAHYAALFANDGAFLILTPIYIAMLLALGFSRGATLAFIMAAGFIADTASLPLIYSNLYNIYSADFFKLGFSEYA GNGRGRLLFTyIYLLGAaYAFLFANDGAFLILTPIYIAMLLALGFSkgtTLAF ! MAFGFIADTASLPLIYSNLYNIYSADFFkLGFtEYA

arsB-BAB91586
arsB-AXD55260
arsB-CED95445
arsB-AKJ19535
arsB-AHD11464
arsB-CDR86494

$\begin{array}{llllllllll}181 & 190 & 200 & 210 & 220 & 230 & 240 & 250 & 260 & 270\end{array}$

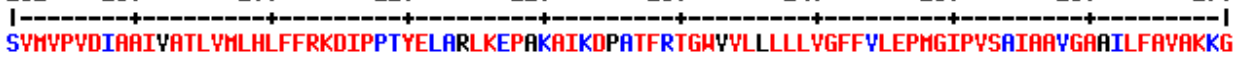
SWHYPYDIAAIIATLYHLHLFFRKDIPPTYDLALLKAPYKAIKDLATFRTGHIYLILLLYGFF YEPLGIPYSAIAAYGAYILFAYAKRG

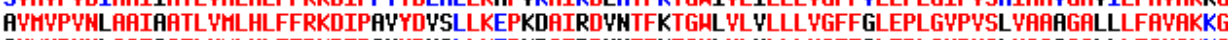

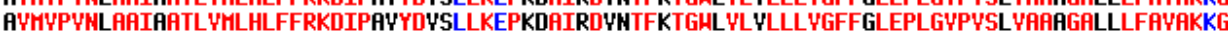
AYMYPUNLAAIAATLYMLHLFFRKDIPAYYDYSLLKEPKDAIRDYNTFKTGLLYLYLLLYGFFGLEPLGUPUSL YAFAGALLLFAYAKKG AYMYPYNLAAIAATLYMLHLFFRKDIPAYYDYSLLKEPKDAIRDYNTFKTGHLYLYLLLYGFFGLEPLGYPYSL YAFAGGLLLFAYAKKG

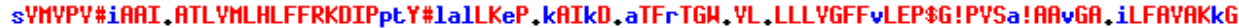

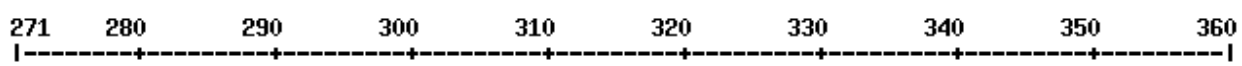

arsB-BAB91586 arsB-AX055260 arsB-CED95445 arsB-AKJ19535

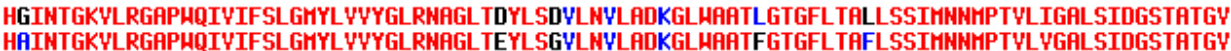

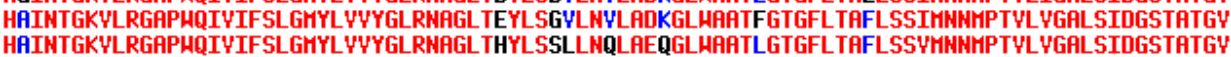
HATNTGKYLRGAPHQIYIFSLGHYLYYYLRAGLTHYLSSLLNQLAEQGLHAATLGTGFLTAFLSSYMNMMPTYLYGALSIDGSTATGY HAINTGKYLRGAPHOIYIFSLGMYLYYYGLRNAGLTHYLSSLLNOLAEOGLHAATLGTGFLTAFLSSWMNMMPTYLYGALSIDGSTATGY

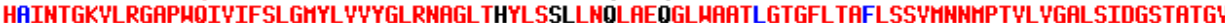
HaINTGKYLRGAPHQIYIFSLGMYLYYGLRNAGLT, YLS, vLHVLA\#kGLHAATIGTGFLTAfLSS ! MNHMPTYL! GALSIDGSTATGY

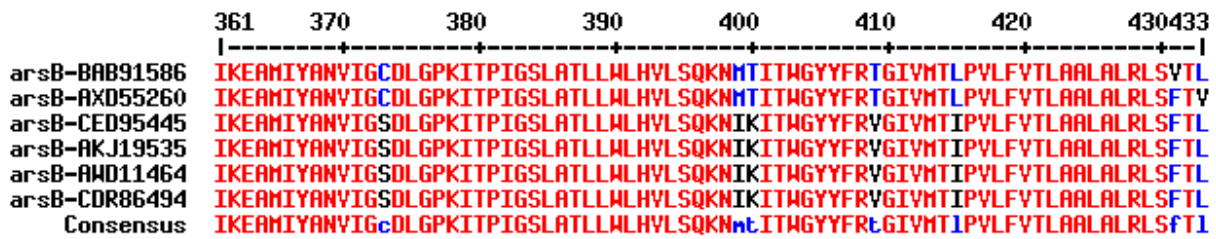

Fig.5A. Multialign of Salmonella plasmid-associated ArsB transporter. Few mutations were detected with two plasmids types where, LF vs IL at 9 amino acid, KST vs RGA at 137 amino acid, PA vs VN at 119 amino acid and AY vs PI at 208 amino acid are predominant. Proteins ids. CED95445, AKJ19535 and AWD11464 are one type cluster. 


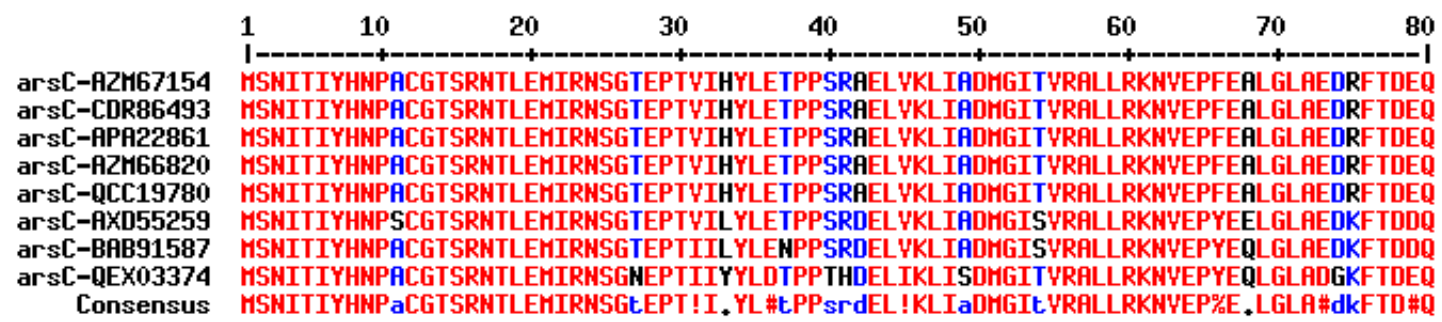

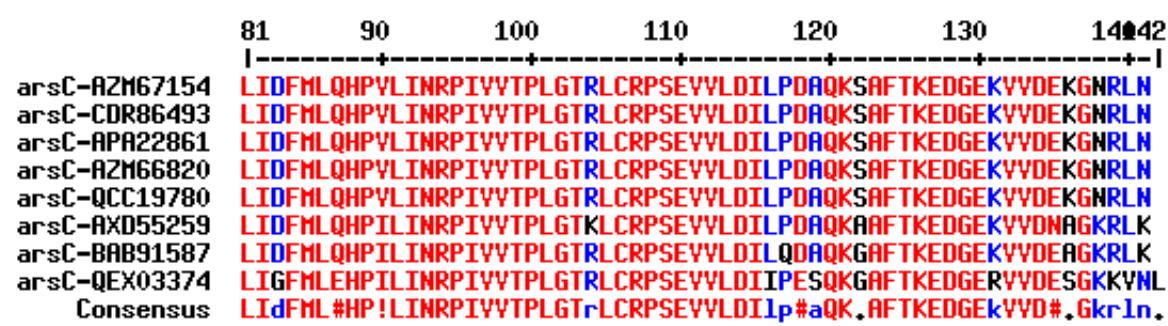

Fig.5B. Detection of mutations in Salmonella enterica plasmid-associated ArsC protein. In major substitution was detected in QEX03374 at 40 (SRA vs THD), at 74 (DR vs GK) and point mutations at 27, 49,68, 83, 104, 119, 131, 136 and 142 amino acids. Point mutations are in AXD55259; $\mathrm{A}$ vs $\mathrm{S}$ at $11, \mathrm{H}$ vs $\mathrm{L}$ at $33 \mathrm{~A}$ vs $\mathrm{E}$ at $68, \mathrm{R}$ vs $\mathrm{K}$ at 75 and $\mathrm{R}$ vs $\mathrm{K}$ at 104 amino acids.
I

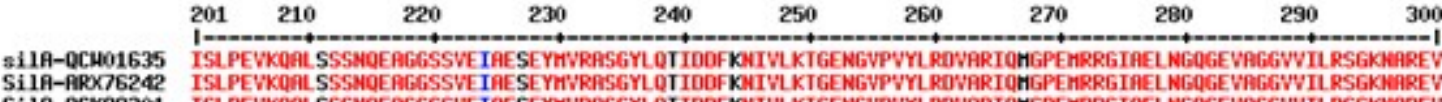

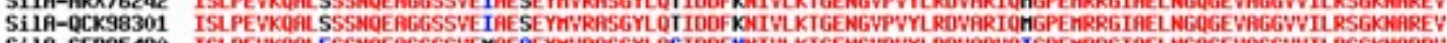

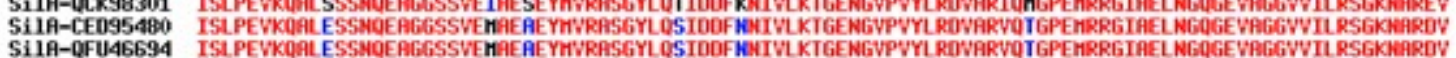

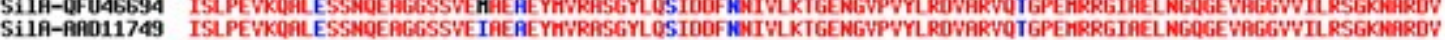

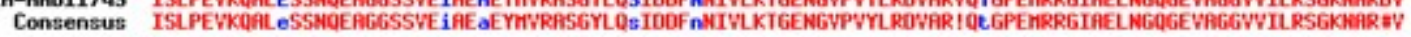 $\begin{array}{lllllllllll}1 & 10 & 20 & 30 & 40 & 50 & 60 & 70 & 80 & 90 & 100\end{array}$
SilB-0C401634 SilB-fRX76243

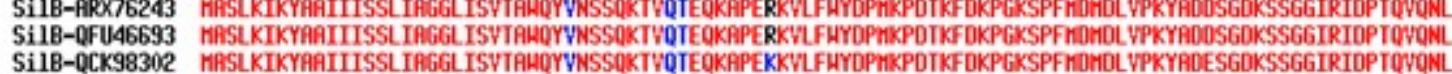

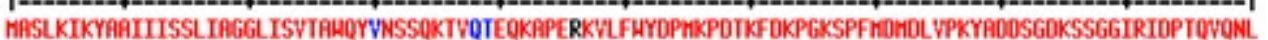

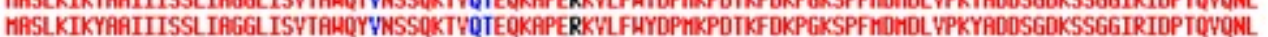

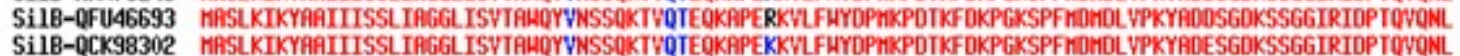

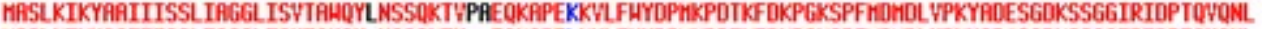
Consensus

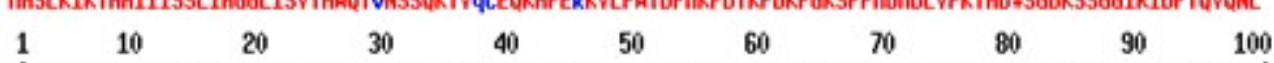

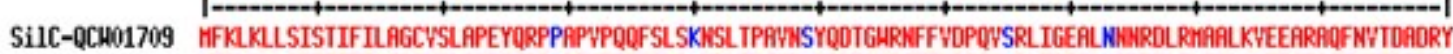

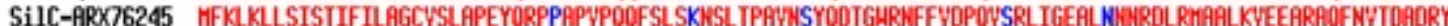

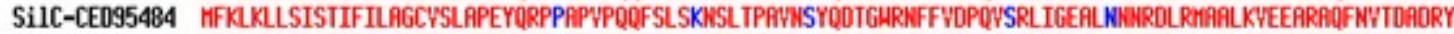

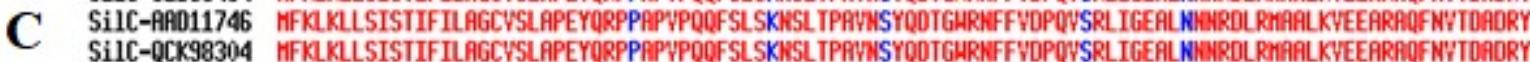

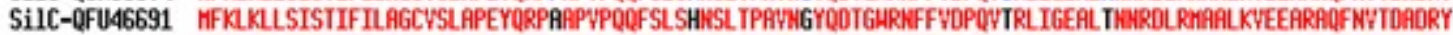

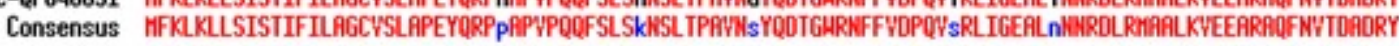

Fig.6. Mutations of plasmid-associated SilA/B/C of Salmonella enterica. Parts of the SilA (A), SilB (B) and SilC (C) protein alignments were shown with multiple mutations. SilA protein id. AAD11749, SilB protein id. CED95481 and SilC protein id. QFU46691 have more mutations. Such genes were also assigned as $\mathrm{CusA}, \mathrm{CusB}$ and $\mathrm{CusC}$ as $\mathrm{Ag}+/ \mathrm{Cu}+$ double resistance was observed, 
1 mstlkitgmt cdscavhvkd alekvpgvqs advsyakgsa klaievgtsp daltaavagl

61 gyratladap svstpgglld kmrdligrnd ktgssgalhi avigsggaam aaalkaveqg

121 arvtliergt iggtcvnvgc vpskimiraa hiahlrresp fdggiaattp tiqrtallaq

181 qqarvdelrh akyegilegn paitvlhgsa rfkdnrnliv qlndggervv afdrcliatg

241 aspavppipg lkdtpywtst ealvsetipk rlavigssvv alelaqafar lgakvtilar

301 stlffredpa igeavtaafr megievreht qasqvaying egdgefvltt ahgelradkl

A 361 lvatgrapnt rklaldatgv tltpqgaivi dpgmrtsveh iyaagdctdq pqfvyvaaa

421 gtraainmtg gdaalnltam pavvftdpqv atvgyseaea hhdgiktdsr tltldnvpra

481 lanfdtrgfi klvveegsgr ligvqavape ageliqtaal airnrmtvqe ladqlfpylt

541 mveqlklaaq tenkdvkqls ccaq -MerA

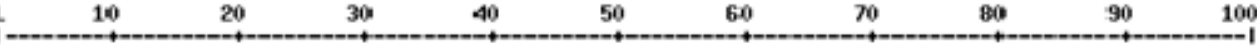

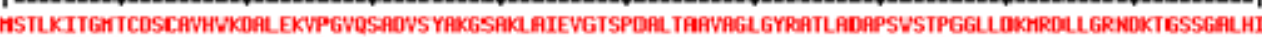
MerA-0C401658 ASTLKT

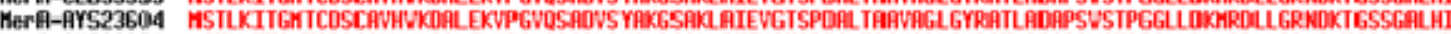

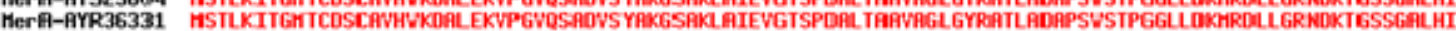

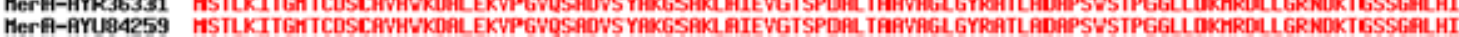

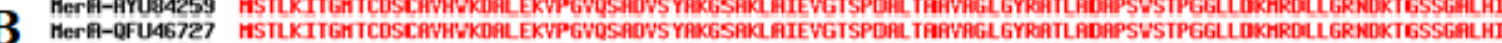

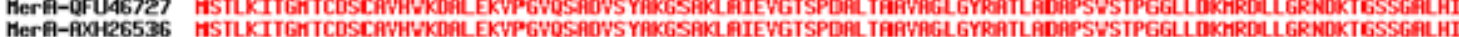

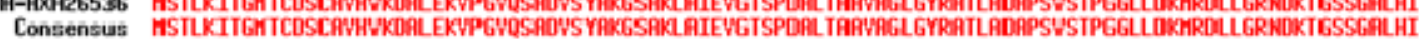

1 mllktsrrtf lkgltlsgva gslgvwsfna rsslslpvaa slqgtqfdlt igetavnitg

61 serqakting glpgpvlrwk egdtitlkvk nrlneqtsih whgiilpanm dgvpglsfmg

121 iepddtyvyt fkvkqngtyw yhshsglqeq egvygaiiid agepepftyd rehvvmlsdw

181 tdenphsllk klkkqsdyyn fnkptvgsff rdvntrglsa tiadrkmwae mkmnptdlad

241 vsgytytylm ngqaplknwt glfrpgekir lrfingsamt yfdiripglk mtvvaadgqy

301 vnpvtvdefr iavaetydvi vepqgeayti faqsmdrtgy argtlatreg lsaavpldp

361 rplltmedmg mggmghdmag mdhsqmggmd nsgemmsmdg adlpdsgtss apmdhssmag

C 421 mdhsrmagmp gmqshpaset dnplvdmqam svspklndpg iglinngrkv ltyadlksrf

481 edpdgrepgr tielhltghm ekfawsfngi kfsdaapvll kygerlritl indtmmthpi

541 hlhgmwsdle dengnfmvrk htidvppgtk rsyrvtadal grwayhchll yhmemgmfre 601 vrvee -PcoA

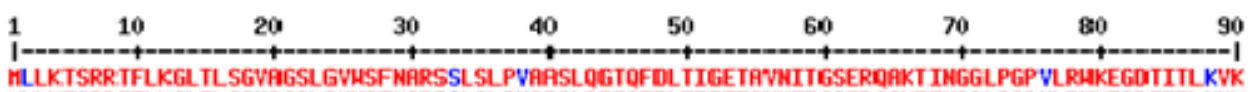
PcoA-ASF62665 MLKTSRRTFLKGLTLSGVAGSLGVHSFNARSSLSLPVARSLQGTQFDLIIGETAVWITGSERQRKT IMGGLPGPVLPAKEGDIITLKVK
PGoA-AXR99430

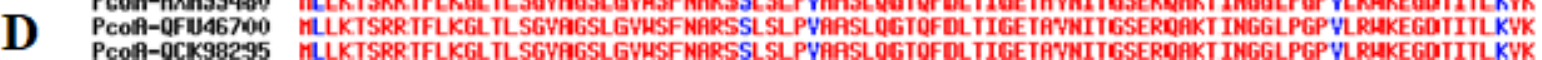

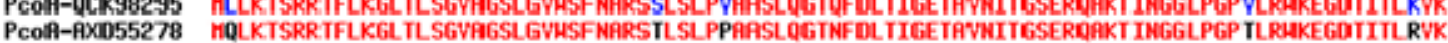

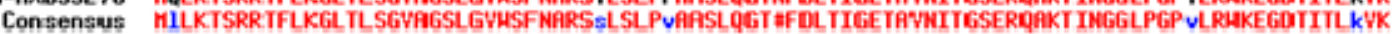

Fig.7. Multialign of Mercuric reductase (B) and Copper oxidase (D) showing MerA has no mutation but PcoA has mutations. Full length amino acid sequences of Salmonella plasmidmediated mercuric reductase (A) and copper oxidase (C) are also given. 


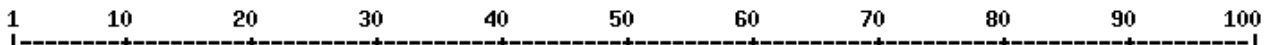
Escherichia-QGH61016 MILHNEFTTLLQQG--NAHFFIPSAILLGALHGLEPGHSKTMMAFFIIAIKGTYRQAYMLGYAFTLSHTAYYHLIAFGGHYISNKFTAESAEPHLQHYSS Enterobacter-fRD6900 Serratia-PHY87035 Serratia-PHY87035 Salnonella-APA22722 Citrobacter-ANZ90174 Klebsiellaf-VDZ63385 KlebsiellaP-CEP74687 KlebsiellaP-AX256414 Consensus

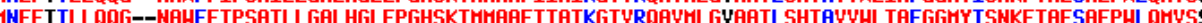
HNEFTTCQ

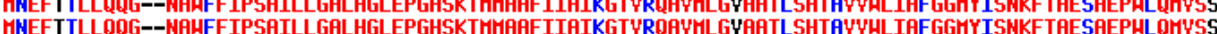

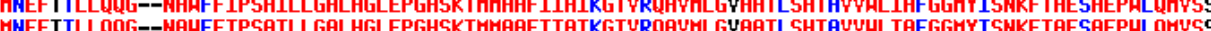

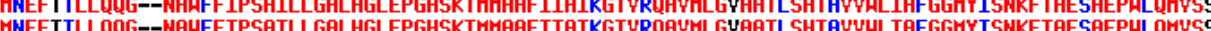

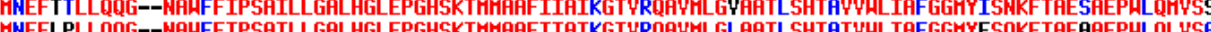
FNEFLPLLQQG--NALFFIPSATLLGALHGLEPGHSKTMMAFFIIAIKGTVRQAYHLGLAFTLSHTATVHLIAFGGGYYFSQKFTAEAFEPHLQLYSA MTDFSTLLQQGYANALLFIPSAILLGALHGLEPGHSKTMIAFFIVAIRGTYKQAVLLGLAATISHTS Y YHLIAFGGMYISQKFTAESAEPHFQLISA MTDFSTLLQQGVANALLFIPSAILLGALHGLEPGHSKTMMAFFIVATRGTVKQAVLLGLAATISHTS Y YLLIAFGGHYISQKFTAESAEPUFQLISA

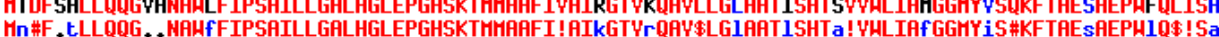

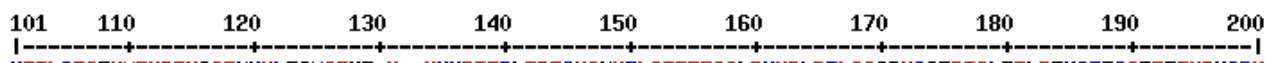

Escherichia-QGH61016 VIILGTAFHMFHRTHSGEKNHLEGMENE-H--HHHDETRLIDTGHGKVELSIFEEGQLPHARLRTLSGQRHASEDISLTTLRENSTISQTFEFYDHGD Enterobacter-ARD6900 YITLGTAFHMFHRTHSGEKNHLEGMQENE-H--HHHDETRLIDTGHGKYELSIFEEGQLPHHRLRTLSGORHASEDISLTTLRENSTISOTFEFYDHGDY

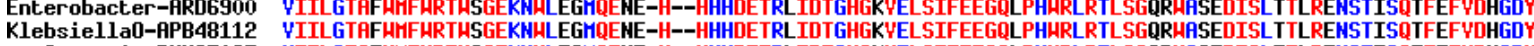
Serratia-PHY87035 YIILGTAFHMFURTHSGEKNHLEGHQENE-H--HHHDETRLIDTGHGKYELSIFEEGQLPHARLRTLSGQRHASEDISLTTLRENSTISQTFEFYDHGDY Salnonella-APA22722 YITLGTAFHMFHRTHSGEKNHLEGHOENE-H--HHHDETRLTDTGHGKVELSIFEEGQLPHHRLRTLSGORHASEDISLITILRENSTISOTFEFYDHGDY Salnonella-APA22722 YIILGTFF

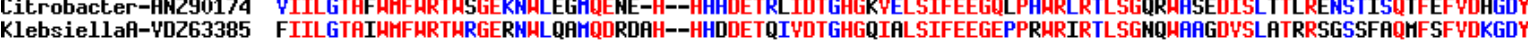

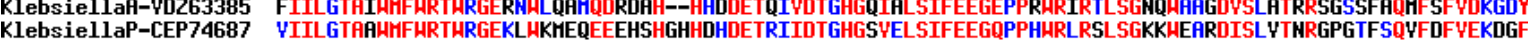

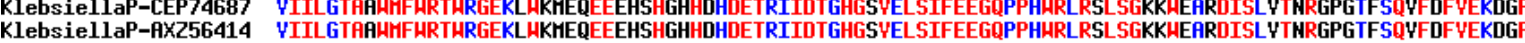

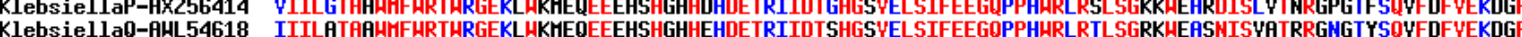

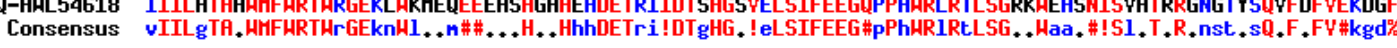

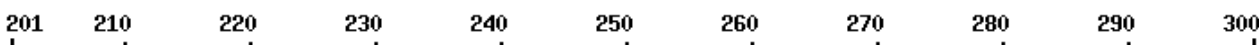

Escherichia-QGH61016 LESTSPIPEPHSFNYRLSLGHRGHYHYDYFFAEHDH---DHDHSELDGLDYNSKEYQDFHELAHANDIKRRFDGKEYTNGQILIFGLTGGLIPCPAHI Enterobacter-fRD6900 LESTSPIPEPHSFHYRLSLGHRGHYHDYYAFAEHDH----DHDHSELDGLDYNSKEYQDFHELAHANDIKRRFDGKEYTNGQILIFGLTGGLIPCPAFI Klebsiella0-APB48112 LESTSPIPEPHSFNYRLSLGHRGHYHDYDYAFAEHDH----DHDHSELDGLDYNSKEYQDAHELAHANDIKRRFDGKEYTNGQILIFGLTGGLIPCPAR Serratia-PHY87035 LESTSPIPEPHSFNYRLSLGHRGHYDYDYAFAEHDH----DHDHSELDGLDYNSKEYQDAHELAHANDIKRRFDGKEYTNGQILIFGLTGGLIPCPAFI Salnonella-APA22722 LESTSPIPEPHSFNYRLSLGHRGHYHDYDYFFAEHDH----DHDHSELDGLDYNSKEYQDAHELAHANDIKRRFDGKEVTNGQILIFGLTGGLIPCPFAI Citrobacter-ANZ90174 LESTSPIPEPHSFNYRLSLGHRGHYHDYDYAFAEHDH----DHDHSELDGLDYNSKEYQDAHELAHANDIKRRFDGKEVTNGQILIFGLTGGLIPCPAFI KlebsiellaA-YDZ63385 LESAQTIPEPHDFNYRLTLGHQRHTHDYDLAF----H----EHHHHELDGLEEGSQAYQDAHERAHANDIQRRFDGREYTNHQILLFGLTGGLIPCPAFI KlebsiellaP-CEP74687 MESALAIPEPHSFDYRLSLGHRGHYHDYDYEFREHEH----DHDHSSLEGLDYNSREYQDAHEKAHANDIKKRFANRSYTTGQIILFGLTGGLIPCPAFI KlebsiellaP-AXZ56414 MESALAIPEPHSFDURLSLGHRGHYHDYDYEFREHEH----DHDHSSLEGLDYNSREYQDAHEKAHFNDIKKRFANRSVTTGQIILFGLTGGLIPCPAFI KlebsiellaQ-fHL54618 MESALAIPEPHSFDYRLSLGHRGHYHDYUEFREHEHGHDHDHDHSALEGLDYNSREYQDAHEKAHANDIKKRFANRSYTTGQIILFGLTGGLIPCPAAI Consensus $\quad$ ESa..IPEPHsF\#YRLsLGHrgHvHDYDvaF,eh.H.....\#HdHseL\#GL\#vnS, eYQDAHE. AHANDIkrRFdgreVTngQIIIFGLTGGLIPCPAFI

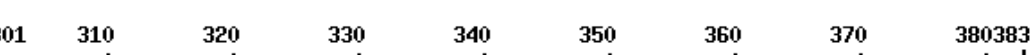

$1-$

Escherichia-QGH61016 Enterobacter-ARD6900

Serratia-PHY87035

Salnonella-APA22722 Citrobacter-ANZ90174 Klebsiellaf-YDZ63385 KlebsiellaP-CEP74687 KlebsiellaP-AX256414 KlebsiellaQ-fHL54618
Consensus

TYLLICLQLKALTLGATLYYCFSIGLALTLYTYGYGAFISYRQYAKRHSGFNTIARRAPYISSALIAFYGIYMGIHGHNGLYH TYLLICLOLKALTLGATL YYCFSTGLALTLYTYGYGAAISYROYAKRHSGFNTIARRAPYISSAL TAAYGTYMGIHGHNGL YH TYLLICLOLKALTLGATL YYCFSTGLALTLYTYGVGAAISYRQYAKRHSGFNTIARRAPYISSALTAAYGTYMGIHGHNGLYH TYLLICLOLKALTLGATLYYCFSIGLALTLYTYGGAAISYROYAKRHSGFNTIARRAPYISSALIAAYGIYMGIHGHNGLYH TYLLICLOLKALTLGATLYYCFSIGLALTLYTYGYGAAISYROYAKRHSGFNTIARRAPYISSALIAAYGTYMGIHGHNGLYH TYLLICLOLKALTLGATLYYCFSIGLALTLYTYGYGAFFSYROYAKRHSGFNTIARRAPYISSALIAAYGIYHGIHGHNGLYH TYLICIOLKALTLGATLYLSFSIGLALTLYTYGYGAAYSYROYAKRHSGFNTLARRAPYFSSYLIGAYGIYMATHGYLGURG

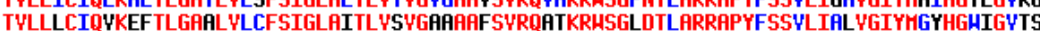

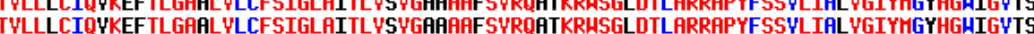
TYLCCIQYKEFTLGAHLYLCFSIGLAIT YSYGAAFAFSYRQATKRHSGLDTLARRAPYFSSYLIALYGIYMGYHGHIGYTS

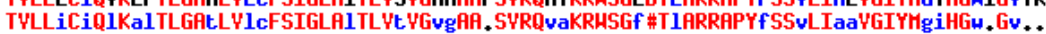

Fig.8. Multialign analysis of plasmid-mediated $\mathrm{Ni}++/ \mathrm{Co}++$ Transporter RcnA. E. coli, E. cloacae, S. enterica, K. oxytoca, S. marcessens RcnA appears identical but I327F mutation in $C$. fruendii where as other Klebsiella species like $K$. pneumoniae, $K$. aerogenes and $K$. quasipneumoniae have more mutated forms (a new lineage) of RcnA transporter with "VA" two amino acids insertion at 11 amino acid position. $K$. quasipneumoniae RcnA has a four amino acids (GHDH) insertion at 234 amino acid position where as a four amino acid deletion (AEHD) at amino acid position 230 of Klebsiella aerogenes.

\section{Discussion}

Analysis suggested that most Salmonella enterica have acquired MDR plasmids and many of them accumulated also toxin genes and virulence genes increasing pathogenesis. Rahman et al has recently demonstrated by WGS that gyrAB mutations and increased in non-H58 Salmonella typhi (genotype 4.3.1) may be a threat to South Asian population (Rahman et al.2020). However, blaTEM, catA1, dhfrA7, sul1, sul2, strAB and gyrase A subunit mutations were detected where as our review demonstrated the presence of blaOXA1, blaCMY and blaNDM like deadly beta-lactamases (Table-1). Holt et al demonstrated the emergence of IncHII MDR plasmids in Salmonella typhi and our search demonstrated the 
existence of IncH1 (pA3T, pHK0653), IncF (pSH696_135, pFORC19), InCI1 (p9134, pSH1148_107), and IncFII (pGDD25-16) (Holt et al. 2011). We detected extended spectrum $\beta$-lactamases in few plasmids (pRH-1238, pGDD25-16 and pA3T) as reported recently (Klemn et al. 2018; Banerjee et al. 2018). Whole genome sequencing (WGS) of Salmonella enterica were done considerably and we analyzed few sequence data to check the presence of mdr genes and drug efflux genes (Parkhill et al. 2001). Heavy metals $(\mathrm{Co}++/ \mathrm{Ni}++/ \mathrm{Cr}++)$ transporter like czcCB and chrAB were not detected in Salmonella enterica but widely distributed in Acinetobacter sp and Pseudomonas sp (protein ids. MPS58401, KHV65566, APW48833 and APW48831/32 but Salmonella enterica RcnA Co++/Ni++ transporter (protein ids. CDR86475, APA22722,AVS55158) may perform the similar protection from heavy metals.

Highly toxic metal ions like $\mathrm{Ag}^{+}, \mathrm{AsO}^{-2}, \mathrm{AsO} 4\left(^{-3}\right), \mathrm{Cd}^{+2} \mathrm{Co}^{+2}, \mathrm{CrO} 4\left({ }^{-2}\right), \mathrm{Cu}^{+2,} \mathrm{Hg}^{2+}, \mathrm{Ni}^{+2}, \mathrm{~Pb}^{2+}$, $\mathrm{TeO}_{3}\left({ }^{-2}\right), \mathrm{Tl}^{+}$and $\mathrm{Zn}^{2+}$ were modulated in bacteria by various mechanisms like metal efflux (SilABC for $\mathrm{Ag}^{+} / \mathrm{Cu}^{+2}$ or $\mathrm{Czc}$ for $\mathrm{Cd}^{+2} / \mathrm{Co}^{+2}$ ) and enzyme-mediated transformations like oxidation-reduction (mercuric reductase, multicopper oxidase), metal-binding proteins (silE, metallothionine, chaperone copZ) or methylation-demethylation to control intracellular concentrations of heavy metal ions that may be inhibitory sulphydryl complexes with enzymes (Nies, 1999). Resistance to inorganic mercury, $\mathrm{Hg}^{++}$as well as organomercurials, such as $\mathrm{CH}_{3} \mathrm{Hg}^{+}$and phenylmercury required mer locus involving a series of metal-binding and membrane transport proteins as well as the enzymes mercuric reductase and organomercurial lyase. A high frequency resistant Salmonella, Pseudomonas and Bacillus genera bacteria to mercury $(10 \mathrm{mg} / \mathrm{L} ;<10 \mathrm{ppm})$ and other heavy metals were reported in environmental water resources where co-resistance were detected to ampicillin, chloramphenicol, tetracycline and streptomycin (60-80\%) as well as $40 \%$ resistant to all four drugs.

In this review, we have presented the molecular view of MDR plasmids in different Serovar of Salmonella enterica, analyzing the GenBank database. Such molecular biology technology rely on Drug Selection of Salmonella enterica, Plasmid Isolation from MDR bacteria and DiDeoxy Sanger DNA sequencing of the Plasmid DNA following GenBank submission (www.ncbi.nlm.nih.gov/genbank).

Arsenic-Antimony toxicities were balanced by arsABCH locus in bacteria and arsenic resistant genes were located in few Salmonella plasmids like pRH-R27, pIncH12, 
pFSAN096147 and pSA20044414 but AarsB arsenic transporter were very abundant in $E$. coli (protein id. MHS90779), K. pneumoniae (protein id. ARR90324) and E. cloacae (protein id. VAL63027). Arsenate reductase (arsC) is glutaredoxin-dependent small enzyme (protein id. WP_000065805) and arsH is arsenic-binding protein (protein id. WP_000130816) whereas arsA is metal efflux-mediated ATPase (protein id. WP_0011057014), all involved in arsenic resistance.

Tellurium resistance locus (terXYABDEFW) is abundant in large Salmonella plasmids like pIMP4-SEM1, pIncH12, pFSAN096147, p09-036813-1A_261, pJXP9, pCFSA300-1, p280_12888 and p200k. TerC protein (346aa) mediates telluriun ion efflux and also abundant in E. coli plasmids (pTE63) with association of terB and terE (Taylor, 1999). $\mathrm{TeO}_{3}^{-2}$ resistance determinants found in extrachromosomal elements include IncHI-2 (Whelan et al., 1997) and pMER610 plasmids (Jobling \& Ritchie, 1988; Hill et al., 1993). The unique structure of the Klebsiella pneumoniae TerB protein (151 AA residues, KP-TerB) has recently been determined (Chiang et al., 2008). TehA /B type genes have been found in Salmonella enterica serovar Typhi (CAD01716 and CAD01717), S. enterica serovar Typhimurium (NP_460568 and NP_460567) as well as in Shigella sp (YP_403356 and YP_689244) and Haemophilus inflfluenzae (YP_248222 and YP_249313) (Hill et al. 1983; Bradley, 1985).

Abundance of tellurium resistance genes is obscure as it is not an essential element like zinc but its applications in electronics, optics, batteries and mining industries have expanded during the last few years, leading to an increase in environmental contamination. Gold ores containing Tellurium are calaverite (AuTe2), sylvanite (AgAuTe4), and nagyagite $[\mathrm{AuPb}(\mathrm{Sb}$, $\mathrm{Bi}) \mathrm{Te} 2-3 \mathrm{~S} 6]$ and thus gold use increase may correlates its abundance in water. $\mathrm{TeO} 3\left({ }^{-2}\right)$ may cause garlic like smell of dimethyltellurite on ingestion of bismuth salt contaminated with tellurite (Cairnes, 1911) whereas, in another mechanism of detoxification, $\mathrm{TeO} 3\left({ }^{-2}\right)$ was reduced to $\mathrm{Te}\left({ }^{0}\right)$ causing precipitation because $\mathrm{TeO} 3\left({ }^{-2}\right)$ was very toxic to bacteria at $<1 \mu \mathrm{g} / \mathrm{L}$ concentration. $\mathrm{TeO} 3\left({ }^{-2}\right)$ could also be reduced chemically to lower oxidation states by glutathione or by other reduced thiol-containing proteins (metallothionine) with drastic decrease in the concentration of antioxidant molecules such as glutathione and cysteine causing a phenotype of higher $\mathrm{TeO} 3\left({ }^{-2}\right)$ tolerance. In this context, mutants of cysteine biosynthetic pathway have shown highly sensitive to telleurite (Dyllick-Brenzinger et al. 2000; Fuentes et al.2007). Prevalence of $m d r$ genes and metal resistant genes were also demonstrated in many Salmonella sp isolated from food animals ( $\mathrm{Na}$ et al. 2020; Anwar et al. 
2020). Surprisingly, ampC beta-lactamse producing plasmids were not detected in the database but many papers had detected such gene in Salmonella sp (Roschanski et al. 2014). The genetic exchange and acquisition of mdr genes were happed in the gut and thus gut microbiome plaed a central role in shaping both mdr and metal resistant genes (Jain et al. 2018). WGS of Salmonella has showed the existence of MDR-islands in Salmonella genome and thus virulence and multi-resistance will be more prominence in Salmonella infections (Saroj et al. 2008; Liu et al. 2009; Sudhanthirakodi et al. 2016; Parkhill et al. 2018; Luo et al. 2020)

\section{Conclusion}

We explained the recent salmoniasis outbreaks in India as well as abroad due to over expression of plasmid-mediated $m d r$ genes, drug efflux genes as well as metal resistant genes which have acquired when Salmonella spends its life in the contaminated water originated due to huge expansion of metal industry, coal industry as well electronics industry. We presented small plasmids with only metal resistant genes or drug resistant genes or toxin genes. However, combination of such plasmids with $62.5 \mathrm{~kb}$ F' conjugative plasmids created large mdr conjugative plasmids accumulating different genes that might not necessary for drug resistance. The localization of complete metal resistant operons like sil, cus, mer and ter with 5-15 metal resistant genes in large plasmids indicated that live stocks (pig, chicken, goat) grew in the metal contaminated soil and water with poor hygienic condition. Such report thus confirmed the spread of animal salmoniasis and Salmonella enterica could be located in cow milk and chicken meat. Salmonella typhi plasmids also analyzed to dictate same notion indicating the passage of the organisms in zoonotic reservoirs have to be carefully studied. Never the less we have authenticated the metal resistant proteins as well as their relation to transposons with $m d r$ genes like blaTEM1, blaNDM1, blaCTX-M15, strAB, $m c r 5 / 9, d h f r$, sull/2 and drug efflux genes like tet $A$, tetB, floR, and $o q x B$. This report is thusa valuable source of drug resistant and metal resistant proteins and their symbiotic relation with respect to co-passage of Salmonella enterica to intestine (to make gut microbiome) and water resources. We are studying the metal resistant bacteria in lakes near Midnapore City where clusters of metal and steel industries are accumulating at the side of the Bombay Road and Kangsabati River of West Bengal, India.

Acknowledgement

I thank Prof. Bidyut Bandhopadhyay, Principal of OIST for help during the work. 


\section{Conflict of interest}

Authors have no conflicts of interest

Ethical issues

This is a review and no animal and human subjects used.

\section{References}

Abraham A, Ifeanyi SS, Muinah F, Ibidunni Oreoluwa BS, Coulibaly KJ, Adeyemi AI. (2019) Plasmid profile and role in virulence of salmonella enterica serovars isolated from food animals and humans in Lagos Nigeria. Pathog Glob Health. 113(6):282-287. doi: 10.1080/20477724.2019.1691364.

Aljahdali NH, Kaldhone PR, Foley SL, Khajanchi BK.( 2019) Whole-genome sequences of 35 incompatibility group I1 plasmid-carrying Salmonella enterica isolates from food animal and clinical sources. Microbiol Resour Announc 8:e00831-19. https://doi.org/10.1128/MRA.00831-19.

Anwar MZ, Zervas A, Hansen LH, Barker G, Anesio AM, Jacobsen CS.(2020) Complete Genome and Plasmid Sequences of Salmonella enterica subsp. enterica Serovar Enteritidis PT1, Obtained from the Salmonella Reference Laboratory at Public Health England, Colindale, United Kingdom. Microbiol Resour Announc. 9(2). pii: e01064-19. doi: 10.1128/MRA.01064-19.

Bakkeren E, Huisman JS, Fattinger SA, Hausmann A, Furter M et al. (2019) Salmonella persisters promote the spread of antibiotic resistance plasmids in the gut. Nature. 573(7773):276-280. doi: $10.1038 / \mathrm{s} 41586-019-1521-8$.

Banerjee K, Sekar P, Krishnan P, Wattam AR, Roy S, Hays JP, et al. (2018) Whole genome sequence analysis of NDM-1, CMY-4, and SHV-12 coproducing Salmonella enterica serovar Typhimurium isolated from a case of fatal burn wound infection. Infect Drug Resist. 2018; 11:2491-5. Epub 2018/12/18. https://doi. org/10.2147/IDR.S16702.

Boyd ES and Barkay T. (2012) The mercury resistance operon: from an origin in a geothermal environment to an efficient detoxification machine. Front Microbiol., https://doi.org/10.3389/fmicb.2012.00349.

Bradley D. (1985) Detection of tellurite-resistance determinants in IncP plasmids. J Gen Microbiol 131: 3135-3137.

Cabello FC, Godfrey HP, Buschmann AH, Dölz HJ. (2016) Aquaculture as yet another environmental gateway to the development and globalisation of antimicrobial resistance. Lancet Infect Dis. 16(7):e127-33. https://doi.org/10.1016/S1473- 3099(16)00100-6.

Calva E, Silva C., Zaidi MB, Sanchez-Flores A, Estrada K et al. (2015) Complete Genome Sequencing of a Multidrug-Resistant and Human-Invasive Salmonella enterica Serovar Typhimurium Strain of the Emerging Sequence Type 213 Genotype. Genome Announc 3 (3), e00663-15.

Chakraborty AK. (2020) Chemical Toxicities of Both Intestine and Environmental Water Caused Genetic Recombination in Bacteria with the Creation of MDR Genes and Drug Void. EC Pharmacology and Toxicology 8(3): 1-14. 
Chakraborty AK, Poria K, Nandi SK (2020) Universal Primer Design for the Detection of Diverged CTX-M Extended Spectrum $\beta$-Lactamases (ESBL) That Give Penicillin and Cephalosporin Resistance During Superbug Infections. In book "Biotechnological Applications in Human Health" Editors: Sadhukhan \& Premi, Springer-Nature Singapore Pte Ltd, Chapter 6, https://doi.org/10.1007/978-981-15-3453-9 6.

Chakraborty AK and Nandi SK (2019) A method of universal primer design for the detection of diverged CTX-M beta-lactamases in multi-drug resistant superbugs. Res \& Rev: J Biotechnol. 9 (2): $1-10$.

Chakraborty AK (2019) Heterogeneous phyto-antibiotics and other future therapeutics against multidrug resistant bacteria. Adv Biochem. 7(2):34-50.

Chakraborty AK (2019) Current status and unusual mechanism of multi-resistance in Mycobacterium tuberculosis. J Health Med Informatics. 10 (1): 328. Doi: 10.4172/2157-7420.1000328.

Chakraborty AK, Pradhan S, Das S, Maity M, Sahoo S, Poria K. (2019) Complexity of OXA BetaLactamases involved in Multi-Resistance. British $J$ Bio-Medical Res. 3 (1): 772-798. Doi: 10.24942/bjbmr.2019.424.

Chakraborty AK, Poira K, Saha D, Halder C, Das S. (2018) Multidrug- Resistant Bacteria with activated and diversified MDR Genes in Kolkata Water: Ganga Action Plan and Heterogeneous Phyto-Antibiotics tackling superbug spread in India. Ame J Drug Deli Ther. 5 (1), Pp.1-9.

Chakraborty AK (2018) Poor correlation of diversified MDR genes in Gonococci plasmids: Does alteration in chromosomal DEGs, PBP2 and Target Mutations sufficient to widespread multiresistance in Neisseria gonorrhoeae? J Health Med Informat 9: 310. Pp. 1-8. doi: 10.4172/21577420.1000310 .

Chakraborty AK. (2018) Nucleic-Acids Based Nanocarriers, in "Nanocarriers for Drug Delivery". eds. Mahapatra et al. chapter-5; pp.155-172, Elsevier Press, Amsterdam. ISBN:978012814. Pp.640.

Chakraborty AK (2017). Multi-drug resistant bacteria from Kolkata Ganga River with heterogeneous MDR genes have four hallmarks of cancer cells but could be controlled by organic phyto-extracts. Biochem Biotechnol Res, 5(1): 11-23.

Chakraborty AK, Maity M, Patra S, Mukherjee S and Mandal T (2017). Complexity, heterogeneity and mutational analysis of antibiotic inactivating acetyl transferases in MDR conjugative plasmids conferring multi-resistance. Res Rev: J Microbiol Biotechnol. 6 (2): 28-43.

Chakraborty AK. Ganga action plan, heterogeneous phyto-antibiotics and phage therapy are the best hope for India tackling superbug spread and control. Ind J Biol Sci 23: 34-51.

Chakraborty AK. (2016) Multi-drug resistant genes in bacteria and $21^{\text {st }}$ Century problems associated with antibiotic therapy. Biotechnol Ind J. 12(12): 114 (pages: 1-20).

Chakraborty AK. (2015) High mode contamination of multi-drug resistant bacteria in Kolkata: mechanism of gene activation and remedy by heterogeneous phyto-antibiotics. Indian J. Biotechnol. 14: $149-159$.

Chu C, Chiu CH (2006) Evolution of the virulence plasmids of non-typhoid Salmonella and its association with antimicrobial resistance. Microbes Infect.;8(7):1931-6. doi: 10.1016/j.micinf.2005.12.026. 
Dyllick-Brenzinger M, Liu M, Winstone TL, Taylor DE \& Turner RJ (2000) The role of cysteine residues in tellurite resistance mediated by the TehAB determinant. Biochem Bioph Res Co 277: 394 400 .

Fuentes DE, Fuentes EL, Castro ME, Perez JM, Araya MA, ' Chasteen TG, Pichuantes SE \& Vasquez CC (2007) Cysteine metabolism-related genes and bacterial resistance to potassium tellurite. J Bacteriol. 189: 8953-8960.

Guerra B, Junker E, Miko A et al. (2004) Characterization and localization of drug resistance determinants in multidrug-resistant, integron carrying Salmonella enterica serotype Typhimurium strains. Microb Drug Resist 10: 83-91.

Gupta,A., Matsui,K., Lo,J.F. and Silver,S. (1999) Molecular basis for resistance to silver cations in Salmonella. Nat. Med. 5 (2), 183-188.

Hill SM, Jobling MG, Lloyd BH, Strike P \& Ritchie DA (1993) Functional expression of the tellurite resistance determinant from the IncHI-2 plasmid pMER610. Mol Gen Genet 241: 203-212.

Holt KE, Phan MD, Baker S, Duy PT, Nga TVT, Nair S, et al. (2011) Emergence of a globally dominant IncHI1 plasmid type associated with multiple drug resistant typhoid. PLoS Negl Trop Dis. 2011; 5(7):e1245. https://doi.org/10.1371/journal.pntd.0001245.

Huang,J., Wang,M., Ding,H., Ye,M., Hu,F., Guo,Q., Xu,X. and Wang,M. (2013) New Delhi metallobeta-lactamase-1 in carbapenem-resistant Salmonella strain, China. Emerging Infect. Dis. 19 (12), 2049-2051.

Jain P, Sudhanthirakodi S, Chowdhury G, Joshi S, Anandan S et al. (2018) Antimicrobial resistance, plasmid, virulence, multilocus sequence typing and pulsed-field gel electrophoresis profiles of Salmonella enterica serovar Typhimurium clinical and environmental isolates from India. PLoS One. 2018 Dec 12;13(12):e0207954. doi: 10.1371/journal.pone.0207954.

Kaldhone PR, Carlton A, Aljahdali N, Khajanchi BK, Sanad YM, et al. (2019) Evaluation of Incompatibility Group I1 (IncI1) Plasmid-Containing Salmonella enterica and Assessment of the Plasmids in Bacteriocin Production and Biofilm Development. Front Vet Sci. 6:298. doi: 10.3389/ fvets.2019.00298.

Khajanchi BK, Hasan NA, Choi SY, Han J, Zhao SH, Colwell RR, Cerniglia CE, Foley SL. (2017) Comparative genomic analysis and characterization of incompatibility group FIB plasmid encoded virulence factors of Salmonella enterica isolated from food sources. BMC Genomics 18:14. https://doi.org/10.1186/s12864-017-3954-5.

Klemm EJ, Shakoor S, Page AJ, Qamar FN, et al (2018). Emergence of an extensively drugresistant Salmonella enterica serovar Typhi clone harboring a promiscuous plasmid encoding resistance to fluoroquinolones and third-generation cephalosporins. mBio 9:e00105-18. https://doi.org/10.1128/mBio.00105-18.

Liu,W.Q., Feng,Y., Wang,Y., Zou,Q.H., Chen,F., Guo,J.T., Peng,YH et al (2009). Salmonella paratyphi C: genetic divergence from Salmonella choleraesuis and pathogenic convergence with Salmonella typhi. PLoS ONE 4 (2), E4510.

Lozano-Leon A, Garcia-Omil C, Dalama J, Rodriguez-Souto R, Martinez-Urtaza J, GonzalezEscalona N. (2019) Detection of colistin resistance $m c r-1$ gene in Salmonella enterica serovar Rissen 
isolated from mussels, Spain, 2012- to 2016. Euro Surveill. 24(16):1900200. doi: 10.2807/15607917.ES.2019.24.16.1900200.

Luo Q, Wan F, Yu X, Zheng B, Chen Y, Gong C, Fu H, Xiao Y, Li L. (2020) MDR Salmonella enterica serovar Typhimurium ST34 carrying mcr-1 isolated from cases of bloodstream and intestinal infection in children in China. J Antimicrob Chemother. 75(1):92-95. doi: 10.1093/jac/dkz415.

Mandal S, Deb Mandal M, Pal NK (2012) Antibiotic resistance of Salmonella enterica Serovar Typhi in Kolkata, India and in vitro experiments on effect of combined chemotherapy. Scientific World Journal 2012:454059. Doi:10.1100/2012/454059. PMID:22666124.

$\mathrm{Na}$ SH, Moon DC, Kang HY, Song HJ, Kim SJ et al. (2020) Molecular characteristics of extendedspectrum $\beta$-lactamase/AmpC-producing Salmonella enterica serovar Virchow isolated from foodproducing animals during 2010-2017 in South Korea. Int J Food Microbiol. 322:108572. doi: 10.1016/j.ijfoodmicro.2020.108572.

Naguib MM, El-Gendy AO, Khairalla A. (2018) Microbial Diversity of Mer Operon Genes and Their Potential Rules in Mercury Bioremediation and Resistance. The Open Biotechnology Journal. 12(1):56-77. DOI: 10.2174/1874070701812010056.

Nies DH. (1999) Microbial heavy-metal resistance. Appl Microbiol Biotechnol. 51:730-750.

Orth D, Grif K, Dierich M P, Würzner R (2007). Variability in tellurite resistance and the ter gene cluster among Shiga toxin-producing Escherichia coli isolated from humans, animals and food. Research Microbiol.158 (2): 105-111. doi:10.1016/j.resmic.2006.10.007. PMID 17317110.

Parkhill J, Dougan G, James K, Thomson N, Pickard D, Wain J, et al. (2001) Complete genome sequence of a multiple drug resistant Salmonella enterica serovar Typhi CT18. Nature. 2001; 413(6858):848. https:// doi.org/10.1038/35101607 PMID: 11677608

Parry CM, Hien TT, Dougan G, White NJ, Farrar JJ. (2002) Typhoid Fever. N Engl J Med.; 347 (22):1770-82. https://doi.org/10.1056/NEJMra020201.

Rahman SIA, Dyson ZA, Klemm EJ, Khanam F, Holt KE, Chowdhury EK, Dougan G, Qadri F. (2020) Population structure and antimicrobial resistance patterns of Salmonella Typhi isolates in urban Dhaka, Bangladesh from 2004 to 2016. PLoS Negl Trop Dis. Feb 27;14(2):e0008036. doi: 10.1371/journal.pntd.0008036.

Rasheed MK, Hasan SS, Babar Z, Ahmed SI. (2019) Extensively drug-resistant typhoid fever in Pakistan. Lancet. 3:242-243.

Roschanski N, Fischer J, Guerra B et al. (2014) Development of a multiplex real-time PCR for the rapid detection of the predominant $\beta$-lactamase genes CTX-M, SHV, TEM and CIT-type AmpCs in Enterobacteriaceae. PLoS One 9: e100956.

Sampei,G., Furuya,N., Tachibana,K., Saitou,Y., Suzuki,T.,Mizobuchi,K. and Komano,T.(2010) Complete genome sequence of the incompatibility group I1 plasmid R64. Plasmid 64 (2), 92-103.

Saroj SD, Shashidhar R, Karani M, Bandekar JR (2008) Distribution of Salmonella pathogenicity island (SPI)-8 and SPI-10 among different serotypes of Salmonella. .J Med Microbiol. 57(Pt 4):424-7. doi: $10.1099 / \mathrm{jmm} \cdot 0.47630-0$. 
Sudhanthirakodi S, Jain P, Chattopadhyay UK, Dutta S. (2016) Non-typhoidal Salmonella isolates from livestock and food samples, Kolkata, India. Journal of Microbiology and infectious Diseases 6(3):113-120.

Summers AO. (1986) Organization, expression, and evolution of genes for mercury resistance. Annu Rev Microbiol. 40:604-634.

Suzuki,S., Komase,K., Matsui,H., Abe,A., Kawahara,K., Tamura,Y et al (1994) Virulence region of plasmid pNL2001 of Salmonella enteritidis. Microbiology (Reading, Engl.) 140 (PT 6), 1307-1318.

Taylor, D. E. (1999). Bacterial tellurite resistance. Trends in Microbiology.7(3): 111115. doi:10.1016/s0966-842x(99)01454-7. PMID 10203839.

Villa,L., Guerra,B., Schmoger,S., Fischer,J et al. (2015) IncA/C Plasmid Carrying blaNDM-1, blaCMY-16, and fosA3 in a Salmonella enterica Serovar Corvallis Strain Isolated from a Migratory Wild Bird in Germany. Antimicrob. Agents Chemother. 59 (10), 6597-6600.

Zhang XZ, Lei CW, Zeng JX, Chen YP, Kang ZZ et al. (2018) An IncX1 plasmid isolated from Salmonella enterica subsp. enterica serovar Pullorum carrying bla operons. Plasmid. 100:14-21. doi: 10.1016/j.plasmid.2018.09.007. 